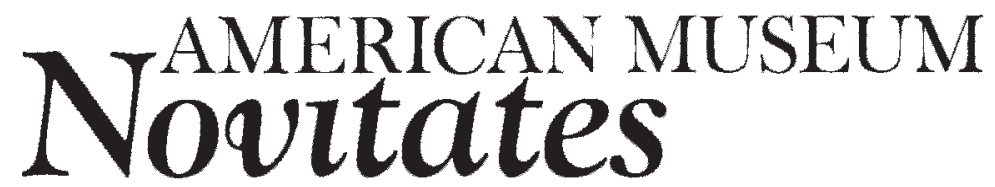

PUBLISHED BY THE AMERICAN MUSEUM OF NATURAL HISTORY CENTRAL PARK WEST AT 79TH STREET, NEW YORK, NY 10024 Number 3617, 29 pp., 1 figure, 6 tables

June 16, 2008

\title{
Estimating body mass in New World "monkeys" (Platyrrhini, Primates), with a consideration of the Miocene platyrrhine, Chilecebus carrascoensis
}

\author{
KAREN E. SEARS, ${ }^{1}$ JOHN A. FINARELLI, ${ }^{2,3}$ JOHN J. FLYNN, ${ }^{4}$ AND \\ ANDRÉ R. WYSS
}

\begin{abstract}
Well-constrained estimates of adult body mass for species of fossil platyrrhines (New World "monkeys") are essential for resolving numerous paleobiological questions. However, no consensus exists as to which craniodental measures best correlate with body mass among extant taxa in this clade. In this analysis, we analyze 80 craniodental variables and generate predictive equations applicable to fossil taxa, including the early platyrrhine Chilecebus carrascoensis.

We find mandibular length to be the best craniodental predictor of body mass. There is no significant difference in predictive value between osteological and dental measures. Variables associated with the mandible and lower dentition do significantly outperform the cranium and upper dentition. Additionally, we demonstrate that modern platyrrhines differ, morphometrically, from early fossil forms. Chilecebus possesses unusual cranial proportions in several key features, as well as proportionally narrow upper incisors and wide upper cheek teeth. These variables yield widely divergent body mass estimates for Chilecebus, implying that the correlations observed in a crown group cannot be assumed a priori for early diverging fossils. Variables allometrically consistent with those in extant forms yield a body mass estimate of slightly less than 600 grams for Chilecebus, nearly a factor of two smaller than prior preliminary estimates.

Scaled to body mass, the brain of Chilecebus is markedly smaller than those of modern anthropoids, despite its lowered body mass estimate advocated here. This finding, in conjunction with a similar pattern exhibited by fossil catarrhines, suggests that increased encephalization arose independently in the two extant subgroups of anthropoids (platyrrhines and catarrhines).
\end{abstract}

\footnotetext{
${ }^{1}$ Department of Animal Biology, University of Illinois at Urbana-Champaign, Urbana, IL 61801.

2 Department of Geological Sciences, University of Michigan, Ann Arbor, MI 48109.

${ }^{3}$ University of Michigan Museum of Paleontology, Ann Arbor, MI 48109.

${ }^{4}$ Division of Paleontology, American Museum of Natural History, New York, NY 10024

${ }^{5}$ Department of Geological Sciences, University of California- Santa Barbara, Santa Barbara, CA 93106.
} 


\section{INTRODUCTION}

Motivated by the discovery of the wellpreserved cranium of the early, fossil platyrrhine (New World "monkey") Chilecebus carrascoensis (Flynn et al., 1995), we explore methods for estimating body mass in fossil platyrrhine species from cranial morphometrics. Adult body mass is highly correlated with a diverse suite of ecological, macroevolutionary, physiological, and life history variables among living mammals (Gittleman and Harvey, 1982; Schmidt-Nielsen, 1984; Gittleman, 1986; Damuth, 1987; McNab and Eisenberg, 1989; Gittleman, 1991, 1993; Gillooly et al., 2005). It follows that improved estimators of body mass for fossil taxa are essential to understanding the biology of extinct species (Gingerich and Smith, 1984; Martin, 1984; Damuth and MacFadden, 1990; Eisenberg, 1990; Jungers, 1990). However, it remains unclear which morphometric variables correlate best with body mass among living mammals, let alone among fossil taxa. Previous attempts to estimate body mass from various skeletal and dental proxies in anthropoids have emphasized the Catarrhini (Old World "monkeys" and hominoids) (e.g., Delson et al., 2000), rather than platyrrhines (Hills and Wood, 1984; Conroy, 1987; Martin, 1990). Since the most reliable morphometric correlates of body mass are identified in the context of comparisons to phylogenetically closely related taxa (Eaglen, 1984; Conroy, 1987; Damuth and MacFadden, 1990; Dagosto and Terranova, 1992), we investigate these associations in platyrrhine primates.

There has been considerable research into various cranial, postcranial, and dental variables as body mass estimators for extinct primates (e.g., Gingerich, 1974; Gingerich et al., 1982; Gingerich and Smith, 1984; Bouvier, 1986; Gingerich, 1990; Martin, 1990; Ruff, 1990; Dagosto and Terranova, 1992; Spocter and Manger, 2007). While a particular variable's reliability as an estimator of body mass for a fossil taxon depends on the strength of the correlation with body mass among extant taxa, those variables that tend to perform better in a statistical sense are not typically the most useful to paleobiologists. Limb bone measures generally correlate better with body mass than do cranial or dental variables. These elements are rare as fossils, however, and when found as isolated elements can be difficult to identify to low taxonomic levels (Damuth and MacFadden, 1990). The most common primate fossils by far are isolated teeth or jaws, elements that typically correlate with body mass more poorly (Gingerich et al., 1982; but also see Dagosto and Terranova, 1992).

Using morphometric proxies to estimate body mass in fossil taxa requires the potentially problematic assumption that the allometric relationship between a given variable and body mass observed among living forms also applies to fossil taxa. As an example, estimates of body mass from different morphometric variables for the early catarrhine Aegyptopithecus yield widely varying results (Radinsky, 1977; Martin, 1990; Dagosto and Terranova, 1992; Simons, 1993). Thus, fossil taxa might be characterized by fundamentally different allometries of the skull and dentition; the more unusual these morphometries are, the more uncertain body size estimates (and derived indices such as encephalization quotients) become. In practice, such deviations are difficult to identify because they require a robust and well-resolved phylogeny (of living and fossil forms) and well-preserved and relatively complete fossil material. To minimize these potential problems with a single estimator, body mass estimates from several proxies often are averaged (e.g., Radinsky, 1971; Martin, 1990). This approach makes the optimistic assumption that inaccuracies among variables offset one another, such that variables yielding overestimates counterbalance those underestimating mass.

To elucidate the pattern of increased encephalization (brain volume scaled to body mass) among platyrrhines, we apply a suite of craniodental body mass estimators to the 20.1 Ma fossil Chilecebus carrascoensis from the Abanico Formation of central Chile (Flynn et al., 1995). Represented by the bestpreserved and -dated early primate skull from South America, Chilecebus provides an excellent test case for application of these methods. The completeness and exceptional preservation allow many of the proxy variables to be 
applied. Moreover, the antiquity of this fossil allows methods of estimating body mass in extinct taxa to be judged against the backdrop of potentially significant evolutionary change in allometry.

\section{METHODS}

\section{Variables, Specimens, and Body Mass Data}

We assembled a suite of 80 morphometric variables from the literature (Gingerich and Schoeninger, 1979; Radinsky, 1981a, 1981b, 1982; Gingerich et al., 1982; Anthony and Kay, 1993; Hartwig, 1993; Kobayashi, 1995). Appendix 1 lists measurement variables and their descriptions. Of these potential body mass proxies, 32 were measurements of osteological features on the cranium and mandible, while 48 were measurements of the dentition. All teeth except the third molars (which do not occur in callitrichines) were measured. Specimens of extant taxa examined were from the collections of the Mammalogy Division, Zoology Department of the Field Museum of Natural History, and the Mammalogy Collections, Division of Vertebrate Zoology of the American Museum of Natural History. In total, 157 specimens representing 17 platyrrhine species were measured. Specimen numbers are given in appendix 2. Extant taxa were chosen to ensure a sample containing at least one species from each of the 15 platyrrhine genera and the full range of body sizes (from $13.5 \mathrm{~kg}$ for Brachyteles arachnoides to 125 grams for Callithrix pygmaea). Body mass data were obtained from the Masses of Mammals Database (v. 3.03: Smith et al., 2003). Average body masses used in the regression analysis are listed by species in table 1. In addition, we measured preserved morphometric variables for the fossil taxon Chilecebus carrascoensis (SGOPV 3213, Museo Nacional de Historia Nacional, Santiago, Chile). Mean measurement values for extant taxa are given by species in appendix 3 .

\section{Allometric Regression Analyses}

Morphometric variables and body masses for the living platyrrhines were log-transformed (base 10) to determine allometric relationships between the variables and body mass. Species average masses were fit to species-average log-
TABLE 1

Body mass for measured extant platyrrhine species Masses given in grams, from Smith et al. 2003.

\begin{tabular}{llr}
\hline \hline \multicolumn{1}{c}{ Genus } & \multicolumn{1}{c}{ Species } & Mass [g] \\
\hline Alouatta & caraya & 5862.5 \\
Aotus & vociferans & 873.0 \\
Ateles & geoffroyi & 5284.9 \\
Brachyteles & arachnoides & 13499.9 \\
Cacajao & melanocephalus & 3800.0 \\
Cacajao & calvus & 5796.0 \\
Callicebus & moloch & 854.7 \\
Callimico & goeldii & 480.0 \\
Callithrix & pygmaea & 125.0 \\
Callithrix & jacchus & 292.0 \\
Cebus & apella & 2500.0 \\
Chiropotes & satanas & 3000.0 \\
Lagothrix & lagotricha & 6300.0 \\
Leontopithecus & rosalia & 535.5 \\
Pithecia & pithecia & 1375.5 \\
Saguinus & mystax & 618.0 \\
Saimiri & sciureus & 743.2 \\
\hline
\end{tabular}

variables using ordinary (Model 1) least-squares regression (Sokal and Rohlf, 1995). Because similarity in morphometry may arise from close phylogenetic relationship (Felsenstein, 1985), we performed phylogenetically corrected regressions (Garland and Ives, 2000), which were executed in the PDAP (Midford et al., 2003) module for the Mesquite software package (Maddison et al., 2002, 2004). Phylogenetic relationships among extant taxa were obtained from molecular phylogenies of the Platyrrhini (Canavez et al., 1999; von Dornum and Ruvolo, 1999) (figure 1). Slopes and intercepts describing the relationship between the morphologic predictor and body mass were calculated for each variable.

To assess a variable's efficacy in predicting body mass, we quantified the relative performance among estimators using the log-likelihood fit of each regression model to the data:

$$
L n L \propto-\frac{1}{2} n L n\left(\frac{E S S}{n}\right)
$$

(Burnham and Anderson, 2002).

In the equation, $n$ is the sample size, and ESS is the error sum of squares of the regression; therefore, the regression likelihood is proportional to its ability to minimize residual variance. Model log-likelihoods were rescaled 


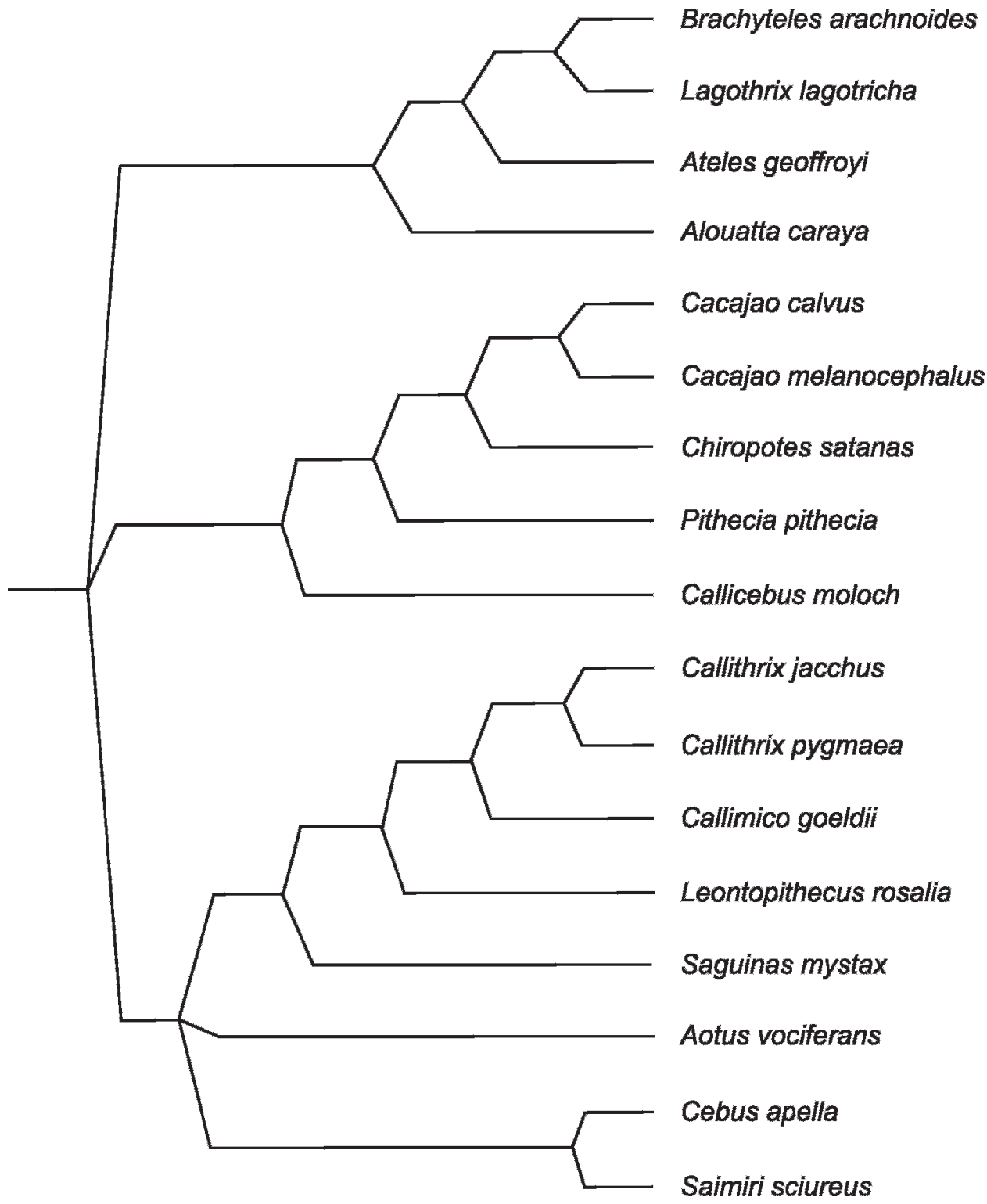

Fig. 1. Cladogram from molecular phylogenies (Canavez et al., 1999; von Dornum and Ruvolo, 1999) of platyrrhine primates used in the phylogenetically corrected regressions of body mass on morphometric variables. This cladogram is a synthetic topology of these two phylogenetic analyses. The topologies for the two analyses were congruent for overlapping taxa, with two exceptions. First the Callicebus/Cacjaol Chiropotes/Pitehca clade was basal to all other Platyrrhini in von Dornum and Ruvolo (1999), but was allied with the Ateles/Bachyteles/Lagothrix/Allouata clade in Canavez et al. (1999). Second, Aotus was allied with Saimiri and Cebus in Canvez et al. (1999), but left in an unresolved polytomy in von Dornum and Ruvolo (1999). Therefore both nodes are conservatively left in polytomies here.

such that the maximum value across all variables was 0 , with poorer predictors having progressively more negative log-likelihoods (Edwards, 1992). We employed a log-likeli- hood difference of 2 (Edwards, 1992; Royall, 1997; Wagner, 2000a, 2000b) as the cutoff for identifying one variable as a significantly better predictor of body mass than another. 


\section{Body Mass Estimation in Chilecebus}

The body mass of the fossil platyrrhine Chilecebus carrascoensis was estimated from 46 measurements preserved in SGOPV 3213, the holotype cranium, using the regression equations generated above from living taxa. We calculated a weighted average of these estimates using the proportional likelihoods for each regression model over the set of all models (Burnham and Anderson, 2002). Model averaging is appropriate when there is no clearly identifiable "correct" model. This method has been employed to a limited extent in previous work (e.g., Radinsky, 1971; Martin, 1990), where the mass estimates from several proxies were averaged to reduce errors associated with any single predictor. However, simply calculating the mean of the individual variable estimates implicitly assumes that all of the variables perform equally well in predicting body mass. Since regression model likelihoods quantify an individual variable's relative predictive ability, a more appropriate averaging technique takes advantage of this information. Using proportional likelihoods, poorly performing models influence the final body mass estimate less, whereas better fitting models more strongly influence the final estimate.

\section{Estimating Relative Brain Size in Chilecebus}

X-ray computed tomographic scans of the Chilecebus carrascoensis cranium were performed on the medical scanner at Children's Hospital of San Diego (CT HiSpeed Adv SYS\#HSA1; $140 \mathrm{Kv}, 170 \mathrm{~mA}$ ) to estimate endocranial volume (Flynn et al., 1995). The skull and surrounding matrix were embedded in modeling clay to better mimic the density of the human body, and scanned at $1.0 \mathrm{~mm}$ resolution. The series of individual axial and transverse scan slices were composited into 3-D images using Cemax VIP software ${ }^{\circledR}$ (Freemont, CA). The resulting brain volume measure was used in conjunction with body mass estimates to determine the relative brain volume in Chilecebus.

To determine whether increased encephalization observed in extant anthropoids was inherited from their last common ancestor, or whether New and Old World anthropoid primates evolved this trait independently, log-encephalization quotients (logEQs) were calculated for the extant catarrhine and platyrrhine taxa considered in Martin (1990). The encephalization quotient (EQ) is the ratio of observed brain volume to expected brain volume for a given body mass (Jerison, 1970; Radinsky, 1971). The metric of interest, however, is not relative volume but deviation of observed volume from the allometric regression of brain volume on body mass, i.e., the natural logarithm of the EQ $(\log E Q)$ (Marino et al., 2004; Finarelli and Flynn, 2007; Finarelli, 2008). Positive logEQs imply larger than expected brain volumes for a given body mass, and negative values the opposite. To assess the relative brain volume for extant platyrrhines and the extinct taxon Chilecebus, we used the allometry relating body mass to brain volume for strepsirrhine primates (as an outgroup to anthropoids) given in Martin (1990) as a frame of reference.

\section{RESULTS AND DISCUSSION}

\section{Body Mass Estimators}

We performed phylogenetically corrected regression of body mass on each of the 80 morphometric variables for the extant taxa. Slopes and intercepts for the predictive equations and the corresponding log-likelihoods for the phylogenetically corrected regressions are given for each variable in table 2 ; scatterplots for the regressions are given in appendix 4 . The relative ability of the morphometric variables surveyed in this analysis to accurately predict body mass, as measured by the loglikelihood fits for the regressions, is highly uneven. The maximum likelihood observed among the variables is for mandibular length, indicating that this variable is the single best predictor of body mass among the 80 variables surveyed. Only one variable (pterygoid-zygomatic length) had a log-likelihood fit within $2 \mathrm{LnL}$ units of mandibular length, and therefore, there is no significant difference in the ability of those two variables to predict body mass among extant platyrrhine species.

The two optimal predictors are both craniomandibular, osteological measurements, not dental variables. Teeth are frequently employed as body mass predictors for fossil mammals (Gingerich, 1974; Legendre, 1986; Legendre and Roth, 1988) because of their 
TABLE 2

Regressions of body mass on morphometric variables for extant taxa

Slopes and intercepts of predictive equations for phylogenetically corrected regressions for each measurement variable (appendix 1) in living platyrrhines sampled (table 1). Also given are $\mathrm{R}^{2}$, error sum of squares (ESS) and the log-likelihood ( $\mathrm{LnL}$ ), rescaled such that the maximum likelihood observed among models (mandibular length) is 0. Measurement regressions are ordered in decreasing $\mathrm{LnL}$. Teeth are upper (U) or lower (L) lengths, widths (anterior or posterior for molars), and areas.

\begin{tabular}{|c|c|c|c|c|c|}
\hline Measurement & Slope & Intercept & $\mathrm{R}^{2}$ & ESS & $\mathrm{LnL}$ \\
\hline Mandibular length & 2.689 & -1.349 & 0.636 & 0.117 & 0.000 \\
\hline Pterygoid-zygomatic length & 2.268 & 0.210 & 0.592 & 0.135 & -1.136 \\
\hline Bizygomatic width & 2.828 & -1.616 & 0.626 & 0.166 & -2.783 \\
\hline Moment arm of the masseter & 1.672 & 0.916 & 0.510 & 0.175 & -3.225 \\
\hline LM1L & 2.205 & 1.822 & 0.449 & 0.195 & -4.077 \\
\hline Skull length & 3.123 & -2.720 & 0.537 & 0.196 & -4.105 \\
\hline Temporal fossa length & 3.202 & -2.233 & 0.374 & 0.198 & -4.193 \\
\hline LM1A & 1.136 & 1.856 & 0.431 & 0.202 & -4.371 \\
\hline Moment arm of the temporalis & 1.760 & 1.434 & 0.434 & 0.213 & -4.786 \\
\hline Mandibular height & 2.016 & 1.010 & 0.516 & 0.215 & -4.841 \\
\hline LM2A & 1.056 & 1.942 & 0.375 & 0.232 & -5.470 \\
\hline Foramen magnum width & 3.339 & -0.253 & 0.387 & 0.232 & -5.474 \\
\hline LP3L & 1.767 & 2.419 & 0.374 & 0.234 & -5.535 \\
\hline LM1WPos & 2.187 & 1.955 & 0.350 & 0.239 & -5.716 \\
\hline Bulla width & 2.939 & 0.302 & 0.327 & 0.241 & -5.781 \\
\hline Occipital width & 2.488 & -0.525 & 0.315 & 0.242 & -5.803 \\
\hline LM1WAnt & 2.269 & 1.968 & 0.353 & 0.244 & -5.864 \\
\hline Condyle Width & 2.614 & 2.008 & 0.447 & 0.244 & -5.879 \\
\hline Cheek tooth row, upper & 1.982 & 0.653 & 0.273 & 0.244 & -5.880 \\
\hline Cheek tooth row, lower & 2.054 & 0.471 & 0.359 & 0.245 & -5.885 \\
\hline Facial height (length) & 2.299 & -0.075 & 0.532 & 0.248 & -6.003 \\
\hline Foramen magnum area & 1.483 & 0.199 & 0.277 & 0.249 & -6.015 \\
\hline LP3A & 0.893 & 2.340 & 0.323 & 0.249 & -6.018 \\
\hline Braincase width & 3.086 & -1.814 & 0.551 & 0.250 & -6.070 \\
\hline LP4L & 1.935 & 2.265 & 0.325 & 0.251 & -6.083 \\
\hline LP4A & 0.980 & 2.192 & 0.303 & 0.251 & -6.099 \\
\hline LP2L & 1.760 & 2.395 & 0.506 & 0.252 & -6.118 \\
\hline LM2WPos & 1.952 & 2.109 & 0.356 & 0.252 & -6.134 \\
\hline LM2WAnt & 2.259 & 1.952 & 0.419 & 0.253 & -6.169 \\
\hline Temporal chord & 3.246 & -1.778 & 0.183 & 0.255 & -6.229 \\
\hline UP3L & 1.866 & 2.326 & 0.306 & 0.261 & -6.396 \\
\hline UP4L & 2.028 & 2.220 & 0.313 & 0.262 & -6.438 \\
\hline LM2L & 1.957 & 1.960 & 0.496 & 0.263 & -6.452 \\
\hline Braincase length & 2.792 & -1.345 & 0.288 & 0.270 & -6.678 \\
\hline LP2A & 0.844 & 2.355 & 0.456 & 0.272 & -6.724 \\
\hline UP3A & 0.932 & 2.138 & 0.275 & 0.273 & -6.764 \\
\hline UP2W & 1.752 & 2.117 & 0.384 & 0.274 & -6.783 \\
\hline UP4A & 1.015 & 2.009 & 0.267 & 0.277 & -6.893 \\
\hline Palate length & 2.025 & 0.388 & 0.394 & 0.281 & -6.985 \\
\hline UP2A & 0.877 & 2.254 & 0.422 & 0.287 & -7.170 \\
\hline LP3W & 1.704 & 2.316 & 0.412 & 0.296 & -7.408 \\
\hline LP4W & 1.830 & 2.205 & 0.209 & 0.297 & -7.450 \\
\hline Foramen magnum height & 2.476 & 0.754 & 0.264 & 0.303 & -7.598 \\
\hline UM1A & 1.080 & 1.747 & 0.399 & 0.309 & -7.743 \\
\hline UP3W & 1.782 & 2.006 & 0.383 & 0.309 & -7.758 \\
\hline UM1L & 2.078 & 1.875 & 0.393 & 0.310 & -7.793 \\
\hline UM2WAnt & 2.212 & 1.674 & 0.398 & 0.311 & -7.813 \\
\hline UP4W & 1.964 & 1.847 & 0.199 & 0.311 & -7.813 \\
\hline UM2WPos & 2.046 & 1.799 & 0.397 & 0.312 & -7.826 \\
\hline
\end{tabular}


TABLE 2

(Continued)

\begin{tabular}{|c|c|c|c|c|c|}
\hline Measurement & Slope & Intercept & $\mathrm{R}^{2}$ & ESS & $\mathrm{LnL}$ \\
\hline UM2A & 0.955 & 1.965 & 0.395 & 0.313 & -7.858 \\
\hline Palate width & 1.830 & 1.034 & 0.400 & 0.315 & -7.908 \\
\hline UM1WAnt & 2.157 & 1.676 & 0.378 & 0.318 & -7.998 \\
\hline Masseteric fossa length & 1.778 & 0.544 & 0.291 & 0.320 & -8.027 \\
\hline Maxillary incisor size & 2.476 & 0.525 & 0.286 & 0.322 & -8.086 \\
\hline LP2W & 1.527 & 2.373 & 0.350 & 0.323 & -8.102 \\
\hline UP2L & 1.683 & 2.427 & 0.353 & 0.323 & -8.118 \\
\hline UM2L & 1.677 & 2.186 & 0.353 & 0.331 & -8.315 \\
\hline $\mathrm{UC1L}$ & 1.497 & 2.293 & 0.459 & 0.333 & -8.355 \\
\hline UM1WPos & 2.130 & 1.695 & 0.326 & 0.344 & -8.624 \\
\hline $\mathrm{LC} 1 \mathrm{~L}$ & 1.403 & 2.527 & 0.328 & 0.349 & -8.728 \\
\hline UC1W & 1.310 & 2.351 & 0.296 & 0.366 & -9.116 \\
\hline $\mathrm{UI} 2 \mathrm{~L}$ & 1.900 & 2.341 & 0.240 & 0.381 & -9.432 \\
\hline Postorbital constriction & 3.056 & -1.526 & 0.234 & 0.395 & -9.720 \\
\hline UI2W & 1.584 & 2.394 & 0.293 & 0.418 & -10.176 \\
\hline Bulla length & 2.383 & 0.061 & 0.181 & 0.425 & -10.308 \\
\hline Condyle length & 2.493 & 0.950 & 0.094 & 0.430 & -10.398 \\
\hline Frontal chord & 2.163 & -0.202 & 0.446 & 0.431 & -10.409 \\
\hline $\mathrm{LC} 1 \mathrm{~W}$ & 1.178 & 2.436 & 0.188 & 0.434 & -10.469 \\
\hline Vertical face height & 1.808 & 0.683 & 0.357 & 0.440 & -10.585 \\
\hline Occipital chord & 2.033 & 0.687 & 0.111 & 0.456 & -10.877 \\
\hline LI2W & 1.569 & 2.340 & 0.111 & 0.480 & -11.284 \\
\hline UI1L & 1.660 & 2.295 & 0.059 & 0.488 & -11.407 \\
\hline Parietal chord & 2.852 & -1.035 & 0.089 & 0.499 & -11.591 \\
\hline LI1L & 1.670 & 2.692 & 0.230 & 0.500 & -11.601 \\
\hline LI1W & 1.427 & 2.489 & 0.141 & 0.515 & -11.847 \\
\hline UI1W & 1.417 & 2.391 & 0.243 & 0.535 & -12.150 \\
\hline $\mathrm{LI} 2 \mathrm{~L}$ & 1.511 & 2.663 & 0.025 & 0.540 & -12.216 \\
\hline Skull vault height & 1.723 & 0.573 & 0.006 & 0.558 & -12.479 \\
\hline Orbit width & 1.791 & 0.885 & 0.003 & 0.610 & -13.192 \\
\hline Basal length of pterygoid fossa & 0.928 & 2.093 & 0.092 & 0.646 & -13.655 \\
\hline
\end{tabular}

higher preservation potential. However, dental measurements are generally considered to be less reliable estimators than osteological variables (including measurements of the postcranium) (Gingerich et al., 1982; Dagosto and Terranova, 1992), potentially reflecting specialized adaptations to unusual diets/food items or unusual food-processing methods (Gingerich and Smith, 1984). To test this assumption, we partitioned the data into osteological (both cranium and mandible), and dental (both upper and lower) splits.

Eight of the 10 best predictors in this analysis are osteological (table 2): mandibular length, pterygoid-zygomatic length, bizygomatic width, moment arm of the masseter, skull length, temporal fossa length, moment arm of the temporalis, and mandibular height. Among these, both mandibular length and pterygoid-zygomatic length exceed the best dental variable by at least $2 \mathrm{LnL}$ units. While osteological features include the best predictors of body mass, they also include the three worst predictors: vault height, orbital width, and pterygoid length. Further, a MannWhitney test (Sokal and Rohlf, 1995) recovers no significant difference in the median rank log-likelihood scores across osteological and dental partitions $(\mathrm{U}=656, p>0.05)$. Thus, while median log-likelihood for the osteological variables is slightly higher than that of dental variables $(-6.45$ versus -7.60$)$, the variance of log-likelihoods for osteological variables also is higher. Thus, while the best predictors are osteological, among platyrrhine primates osteological characters do not universally outperform dental ones.

Among dental variables, the best predictor of body mass is lower M1 length (table 2), a commonly used proxy for body mass in 
mammals (Van Valkenburgh, 1990; Janis et al., 1998a, 1998b). Lower M1 area, another commonly used proxy (Gingerich, 1974; Legendre, 1986; Legendre and Roth, 1988; Finarelli and Flynn, 2006), was the next best estimator and was not significantly different than lower $\mathrm{M} 1$ length $(\mathrm{LnL}$ difference $=$ 0.298). As noted above, the distribution of log-likelihoods for dental variables was less dispersed than the distribution for osteological variables. Eight dental measures (as opposed to two osteological) were within $2 \mathrm{LnL}$ units of the optimal dental score. However, among these, only upper cheek tooth row length was from the upper dentition. A Wilcoxon signedrank test performed on 24 upper/lower pairs of dental measurements demonstrates that variables from the lower dentition significantly outperform their upper dentition counterparts as predictors of body mass $(\mathrm{W}=160, p$ $<0.05)$.

Thus, regression model likelihoods demonstrate: 1) that the single best predictor is mandibular length, and 2) that the lower dentition significantly outperforms the upper dentition in predicting body mass. Thus, it appears that predictors associated with the mandible may outperform those of the cranium among extant platyrrhines. To test this, log-likelihoods were separated into mandibular and cranial partitions, rather than osteological (including the mandible) and dental (including both upper and lower) partitions. Median mandibular log-likelihoods were higher than cranial log-likelihoods $(-6.12$ versus -7.81 ), a significant difference (MannWhitney test, $\mathrm{U}=519, p<0.05$ ).

Intraspecific variability must be a concern when evaluating evolutionary allometries through species mean values. Platyrrhines, and primates in general, are sexually dimorphic (Martin et al., 1994), a feature that leads to a range of variance that is discounted when averaging over species. When estimating body mass for fossil taxa allometries must use species averages. Sex identification for fossil mammals generally is not possible, except in rare instances (e.g., Coombs, 1975; Fleagle et al., 1980; Krishtalka et al., 1990; Van Valkenburgh and Sacco, 2002). This is due to the fact that fossil taxa are often known from a limited number of specimens and rarely represent a population sample for a species. It is therefore difficult to rigorously evaluate sexual dimorphism or other forms of intraspecific variation. However, large degrees of within-species variation can negatively impact the precision of prediction allometries.

More troublesome would be if there were a tendency for the range of variation to increase or decrease as a function of body mass (e.g., Rensch's rule: Rensch, 1950). To assess this potential impact of intraspecific variation on model estimates for extant Platyrrhini, we calculated the difference between log-transformed maximum and minimum values for the 17 species, yielding an observed proportional range (table 3 ). This range was not calculated for Brachyteles due to its low sample size. The observed intraspecific proportional ranges average approximately $14 \%$ of the total observed variation across all taxa. In addition, there is no association between the percentage of total range that the proportional range represents, and the major variable partitions. Mann-Whitney tests (Sokal and Rohlf, 1995) comparing osteological/dental splits $(\mathrm{U}=641$, $p>0.05)$ and mandibular/cranial splits $(\mathrm{U}=$ $818.5, p>0.05)$ were not significant. We also regressed observed proportional range against the species average body mass for each taxon. For each measurement variable, a t-test for the slope of the regression (Sokal and Rohlf, 1995) was not significant; regression slopes ranged from -0.073 to 0.066 with a median value of 0.013 . Therefore, proportional ranges do not vary as a function of species body size.

\section{Body Mass Estimates for Chilecebus}

One of the main objectives in deriving morphometric proxies for body mass among extant taxa is to apply the predictive equations to fossil taxa. Here we apply the body mass proxies derived above to the fossil platyrrhine Chilecebus carrascoensis (Flynn et al., 1995). The only known specimen of this taxon (a skull, SGOPV 3213) lacks the mandible, and pterygoid-zygomatic length (the second best predictor variable) could not be measured. There are, however, 46 measurements that can be evaluated on this nearly complete skull. Of these, 24 variables are osteological and 22 dental. Body mass estimates derived from these variables 


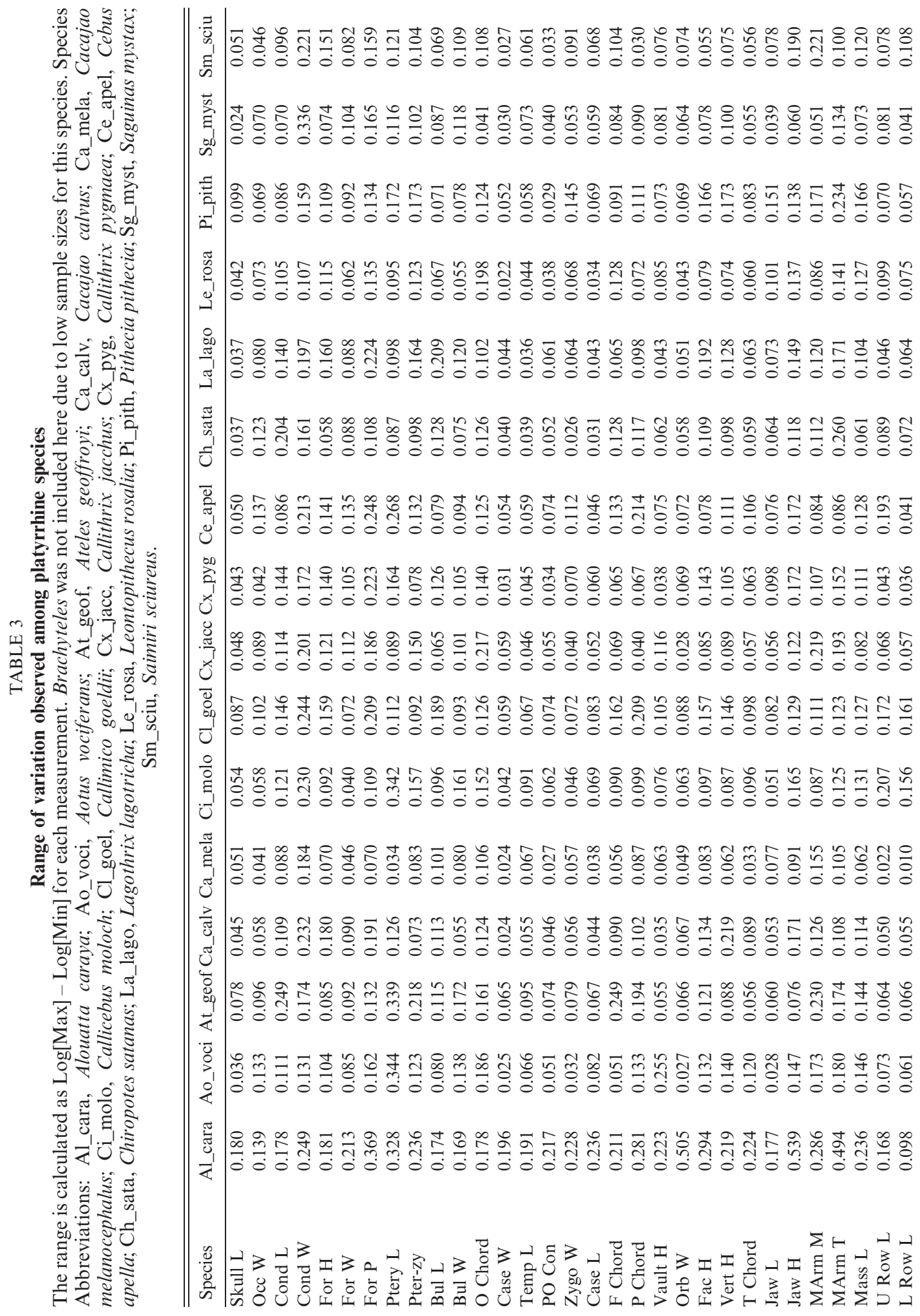




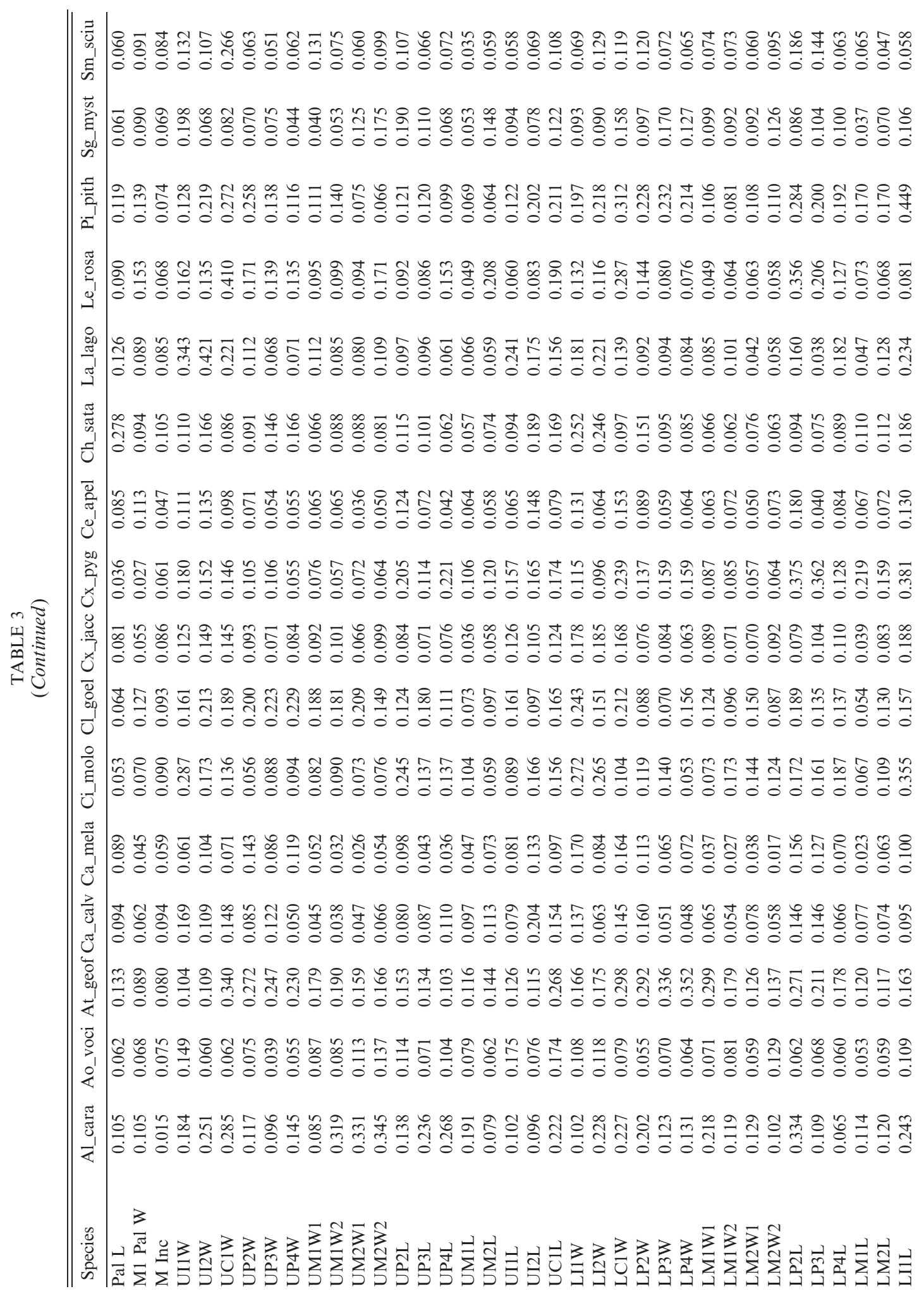




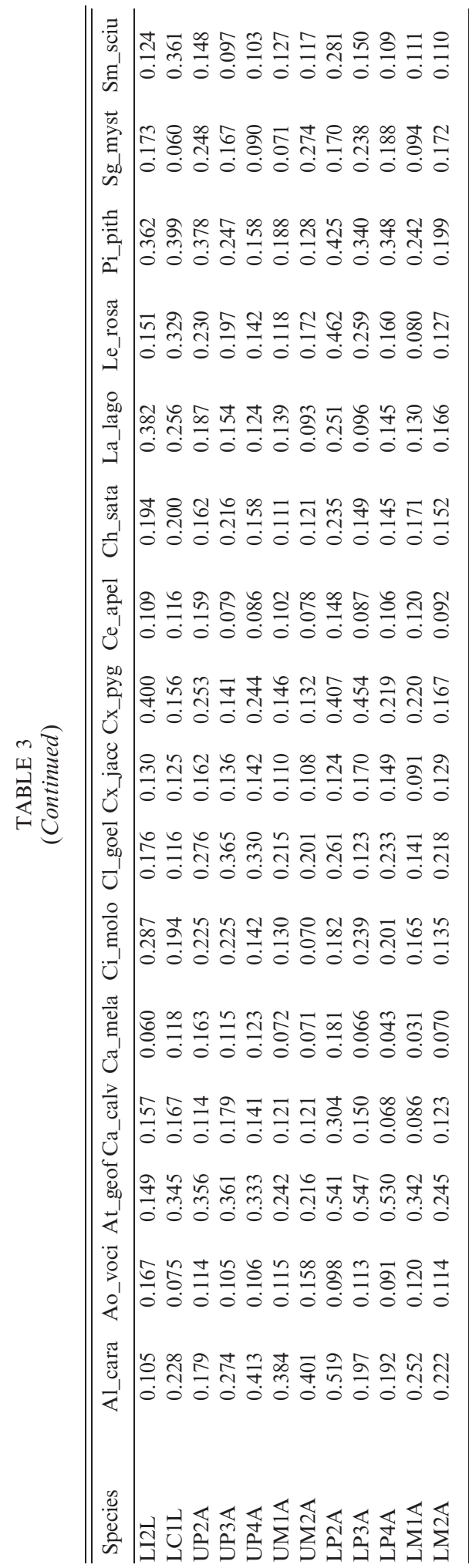

range widely, from about 85 grams (temporalis length) to approximately $1.7 \mathrm{~kg}$ (upper $\mathrm{P} 4$ width), a greater than 20 -fold difference in maximum and minimum estimates (table 4). The arithmetic mean of these estimates is 589 grams (table 4). Within the range of estimates, osteological variables generally produce lower estimates than do the dental variables; body mass estimates derived from osteological variables range from 85 to 1137 grams, with a mean of 494 grams, whereas dental variables yield a range from 374 to 1725 grams, with a mean of 997 grams. In contrast, the weighted average, which incorporates the proportional likelihoods of the regressions to weight individual measurement estimates, yields an estimated body mass of 319 grams (table 4), considerably lower than the simple mean. Notably the weighted average is also lower than the minimum mass estimate generated from the dental variables. Thus, while there is considerable overlap in body mass estimates between the osteological and dental partitions, the weighted-average model demonstrates that the lower estimates are derived from the variables known to be more reliable body mass indicators among extant taxa.

This broad range of body mass estimates for Chilecebus is worrisome with regard to estimating body mass for fossil platyrrhines in general. If these variables conform to the same allometries in Chilecebus as are observed among extant taxa, then all should yield similar mass estimates. To the contrary, our results prove that at least some of these variables must scale differently in Chilecebus than in modern platyrrhines. While this might be interpreted as hindering reliable body mass estimation for Chilecebus, the allometric scalings observed among extant taxa must be assumed to hold for the fossil members of the group in any analysis of this kind. The large range of estimated body masses for Chilecebus is by no means unique among extinct primates; for example, body mass estimates for the basal catarrhine Aegyptopithecus (Kay and Simons, 1980) also vary widely depending on the morphometric proxy employed.

Flynn et al. (1995) originally estimated the body mass of Chilecebus at $1.0-1.2 \mathrm{~kg}$, based on upper cheek tooth regressions across all primates. They noted, however, an unusual 
TABLE 4

Estimated body mass for Chilecebus carrascoensis

Estimates based on morphometric proxies preserved in the holotype cranium. The first set of estimates are based on all of the preserved measurements. The second set relates only the 20 measurements for which Chilecebus conforms to the extant allometry (see text). Individual measurement estimates are given, and their arithmetic mean is presented at the bottom. Weighted estimates refer to a weighted average model using proportional likelihoods as model weights (see text). The sum of these represents the weighted average model and this is also given at the bottom.

\begin{tabular}{|c|c|c|c|c|c|}
\hline \multirow[b]{2}{*}{ Measurement } & \multirow[b]{2}{*}{ LogL Weights } & \multicolumn{2}{|c|}{ All Measurements } & \multicolumn{2}{|c|}{ Reduced Measurement Set } \\
\hline & & $\begin{array}{c}\text { Body Mass } \\
\text { Estimate }\end{array}$ & $\begin{array}{l}\text { Weighted } \\
\text { Estimate }\end{array}$ & $\begin{array}{c}\text { Body Mass } \\
\text { Estimate }\end{array}$ & $\begin{array}{l}\text { Weighted } \\
\text { Estimate }\end{array}$ \\
\hline Skull length & $1.046 \mathrm{E}-02$ & 429.949 & 53.699 & 429.949 & 218.554 \\
\hline Occipital width & $1.916 \mathrm{E}-03$ & 1136.862 & 26.012 & 1136.862 & 105.869 \\
\hline Condyle length & $1.934 \mathrm{E}-05$ & 206.305 & 0.048 & . & . \\
\hline Condyle width & $1.775 \mathrm{E}-03$ & 1007.406 & 21.355 & . & . \\
\hline Foramen magnum height & $3.183 \mathrm{E}-04$ & 336.396 & 1.278 & . & . \\
\hline Foramen magnum width & $2.661 \mathrm{E}-03$ & 865.273 & 27.492 & . & . \\
\hline Foramen magnum area & $1.549 \mathrm{E}-03$ & 476.250 & 8.811 & . & . \\
\hline Basal length of pterygoid fossa & $7.447 \mathrm{E}-07$ & 1040.611 & 0.009 & 1040.611 & 0.038 \\
\hline Bulla length & $2.037 \mathrm{E}-01$ & 317.039 & 0.080 & . & . \\
\hline Bulla width & $2.116 \mathrm{E}-05$ & 100.113 & 2.341 & . & . \\
\hline Occipital chord & $1.959 \mathrm{E}-03$ & 628.653 & 0.090 & 628.653 & 0.366 \\
\hline Braincase width & $1.199 \mathrm{E}-05$ & 444.242 & 7.782 & 444.242 & 31.672 \\
\hline Temporal fossa length & $1.467 \mathrm{E}-03$ & 84.945 & 9.721 & . & . \\
\hline Postorbital constriction & $9.584 \mathrm{E}-03$ & 326.561 & 0.149 & . & . \\
\hline Zygomatic arch width & $3.812 \mathrm{E}-05$ & 85.852 & 40.250 & . & . \\
\hline Braincase length & $3.926 \mathrm{E}-02$ & 546.801 & 5.212 & 546.801 & 21.212 \\
\hline Frontal chord & 7.982E-04 & 424.186 & 0.097 & . & . \\
\hline Parietal chord & $1.913 \mathrm{E}-05$ & 729.496 & 0.051 & 729.496 & 0.208 \\
\hline Skull vault height & $5.868 \mathrm{E}-06$ & 882.893 & 0.025 & 882.893 & 0.104 \\
\hline Orbital width & $2.415 \mathrm{E}-06$ & 155.830 & 0.002 & . & . \\
\hline Facial height (length) & $1.184 \mathrm{E}-06$ & 194.083 & 3.635 & . & . \\
\hline Vertical face height & $1.568 \mathrm{E}-03$ & 455.752 & 0.087 & 455.752 & 0.356 \\
\hline Temporal chord & $1.606 \mathrm{E}-05$ & 564.098 & 8.423 & 564.098 & 34.281 \\
\hline Cheek tooth row, upper & $1.250 \mathrm{E}-03$ & 862.867 & 18.268 & 862.867 & 74.351 \\
\hline Palate width & $6.346 \mathrm{E}-01$ & 408.763 & 1.139 & . & . \\
\hline UI1W & $5.013 \mathrm{E}-03$ & 975.584 & 0.039 & 975.584 & 0.159 \\
\hline UI2W & $2.523 \mathrm{E}-02$ & 1205.903 & 0.348 & 1205.903 & 1.416 \\
\hline $\mathrm{UC1W}$ & $5.299 \mathrm{E}-03$ & 1039.983 & 0.224 & 1039.983 & 0.911 \\
\hline UP2W & $2.072 \mathrm{E}-04$ & 1295.374 & 11.123 & . & . \\
\hline UP3W & $1.773 \mathrm{E}-03$ & 1697.284 & 5.497 & . & . \\
\hline UP4W & $1.764 \mathrm{E}-03$ & 1725.191 & 5.286 & . & . \\
\hline UM1WAnt & $5.876 \mathrm{E}-04$ & 1566.878 & 3.991 & . & . \\
\hline UM2WAnt & $2.334 \mathrm{E}-04$ & 1516.114 & 4.647 & . & . \\
\hline UP2L & $1.954 \mathrm{E}-04$ & 650.189 & 1.469 & 650.189 & 5.977 \\
\hline UP3L & $3.356 \mathrm{E}-06$ & 681.960 & 8.620 & 681.960 & 35.084 \\
\hline UP4L & $2.416 \mathrm{E}-05$ & 665.608 & 8.069 & 665.608 & 32.840 \\
\hline UM1L & $1.803 \mathrm{E}-05$ & 554.851 & 1.736 & 554.851 & 7.064 \\
\hline UM2L & 7.192E-04 & 866.640 & 1.607 & 866.640 & 6.540 \\
\hline UI1L & $2.712 \mathrm{E}-04$ & 374.210 & 0.032 & . & . \\
\hline UI2L & $2.566 \mathrm{E}-04$ & 430.239 & 0.261 & . & . \\
\hline $\mathrm{UC} 1 \mathrm{~L}$ & $2.133 \mathrm{E}-04$ & 774.311 & 1.380 & 774.311 & 5.617 \\
\hline UP2A & $1.140 \mathrm{E}-04$ & 897.992 & 5.234 & . & . \\
\hline UP3A & $2.567 \mathrm{E}-04$ & 1075.035 & 9.403 & . & . \\
\hline UP4A & $2.532 \mathrm{E}-04$ & 1070.204 & 8.231 & . & . \\
\hline UM1A & $1.892 \mathrm{E}-04$ & 910.563 & 2.993 & . & . \\
\hline UM2A & $1.059 \mathrm{E}-03$ & 1106.215 & 3.241 & . & . \\
\hline Averaged Estimates & & 589.559 & 319.486 & 722.252 & 582.619 \\
\hline
\end{tabular}


combination of morphological features in Chilecebus, including a relatively small braincase and the proportions of the upper dentition. Cranial osteological measures tend to produce lower body mass estimates than do dental variables for Chilecebus. However, does this imply that dental variables generally overestimate mass, or that the cranial osteological metrics consistently underestimate it? To determine which measures scale uniquely in Chilecebus relative to extant platyrrhines, we regressed all other variables preserved in Chilecebus against skull length for the set of extant platyrrhine species. This offers a way to describe allometric differences between Chilecebus and the suite of extant platyrrhines. Regression residuals were calculated for Chilecebus and extant taxa relative to each variable's allometry; variables in which the Chilecebus residual was greater than two standard deviations of that observed among the extant taxa were considered variables in which Chilecebus deviates significantly from extant platyrrhine allometry for that variable.

The results of this analysis demonstrate that a unique morphometry relative to living platyrrhines explains the much heavier body mass proposed in the initial description of Chilecebus. Flynn et al. (1995) noted that Chilecebus has proportionally wider upper premolars and molars than extant primates of the same skull length. Here, residuals for all upper cheek tooth widths in Chilecebus do exceed those in extant platyrrhines by more than two standard deviations (table 5). Thus, upper cheek tooth widths (and areas derived from them) will lead to overestimates of body mass. Mesiodistal lengths of both upper incisors of Chilecebus are significantly less than in the extant regression, meaning that these variables produce underestimates of body mass (table 5). Several osteological characters in Chilecebus also deviate significantly from the modern allometries, including: foramen magnum height and width (and the area derived from them), occipital condyle length and width, length and width of the auditory bullae, temporalis length, postorbital constriction, bizygomatic width, length of the frontal chord, orbital width, facial height, and the palatal width at M1 (table 5). All of these are significantly shorter in Chilecebus than predicted by modern allometries, and therefore would yield underestimates of body mass. Thus, no simple pattern accounts for the discrepancy between dental and cranial osteological variable-derived estimates of body mass in Chilecebus, rather various individual variables deviate from the modern allometries, and point to a fundamentally different skull form in Chilecebus relative to extant platyrrhines (Flynn et al., 1995).

Even so, 20 variables from both the osteological and dental partitions do conform to modern allometries, and should, therefore, provide reliable estimates of body mass. Limiting estimates to those variables greatly narrows the range of estimates: 430 to 1206 grams, with an average value of 722 grams (table 4). Excluding those measures not conforming to extant allometries eliminates both the extreme high and low body mass estimates for Chilecebus (e.g., upper P3, upper P4 width, and anterior widths of the upper M1 and upper M2, all of which predict masses $>1.5 \mathrm{~kg}$; temporalis length, bizygomatic width, and width of the auditory bullae predicting masses $\leq 100$ grams). The reduced set of 20 measurements produces a weightedaverage estimate of 583 grams (table 4). We consider this constrained weighted-average to be the most reliable estimate of the body mass for Chilecebus, as this estimate is based on those metrics that can be shown to conform to the extant allometries and utilizes the relative reliabilities of predicting body mass in the extant taxa in weighting the impact of each variable upon the final estimate.

\section{Relative Brain Size in Chilecebus}

Flynn et al. (1995) noted the small braincase of Chilecebus (7.46 cc, based on CT data), and suggested that a low level of encephalization may characterize platyrrhines ancestrally. However, the initial body mass estimate for Chilecebus based on upper cheek teeth (1.0 $1.2 \mathrm{~kg}$ ) is approximately double the 583 gram estimate from this analysis. We have shown that upper cheek tooth widths overestimate body mass in Chilecebus, and therefore the original hypothesis of a relatively small brain in Chilecebus might simply reflect an inflated body mass estimate. 
TABLE 5

Measurements taken on the Chilecebus carrascoensis cranium, and their deviation from the extant allometries for each measurement

Two standard deviations of the residuals of extant taxa around each allometry are given. Values in bold indicate measurements where Chilecebus falls more than two standard deviations from the regression line. Sign indicates whether the measurement is anomalously large $(+)$ or small $(-)$ on Chilecebus, and therefore will over- or underestimate body mass, respectively.

\begin{tabular}{|c|c|c|c|}
\hline Measurement & Chilecebus Residual & 2 Standard Deviations & Sign \\
\hline Occipital width & 0.065 & 0.147 & \\
\hline Condyle length & -0.231 & 0.080 & - \\
\hline Condyle width & 0.100 & 0.090 & + \\
\hline Foramen magnum height & -0.125 & 0.112 & - \\
\hline Foramen magnum width & 0.080 & 0.040 & + \\
\hline Basal length of pterygoid fossa & 0.026 & 0.171 & \\
\hline Bulla length & -0.120 & 0.095 & - \\
\hline Bulla width & -0.233 & 0.079 & - \\
\hline Occipital chord & -0.036 & 0.100 & \\
\hline Braincase width & -0.016 & 0.046 & \\
\hline Temporal fossa length & -0.255 & 0.068 & - \\
\hline Postorbital constriction & -0.077 & 0.067 & - \\
\hline Zygomatic arch width & -0.263 & 0.039 & - \\
\hline Braincase length & -0.047 & 0.110 & \\
\hline Frontal chord & -0.117 & 0.088 & - \\
\hline Parietal chord & -0.017 & 0.114 & \\
\hline Skull vault height & -0.038 & 0.139 & \\
\hline Orbital width & -0.170 & 0.116 & - \\
\hline Facial height (length) & -0.172 & 0.044 & - \\
\hline Vertical face height & -0.085 & 0.086 & \\
\hline Temporal chord & 0.005 & 0.066 & \\
\hline Cheek tooth row, upper & 0.104 & 0.141 & \\
\hline Palate width & -0.217 & 0.216 & - \\
\hline UI1W & 0.023 & 0.145 & \\
\hline UI2W & 0.112 & 0.125 & \\
\hline $\mathrm{UC} 1 \mathrm{~W}$ & 0.077 & 0.175 & \\
\hline UP2W & 0.172 & 0.133 & + \\
\hline UP3W & 0.226 & 0.116 & + \\
\hline UP4W & 0.214 & 0.108 & + \\
\hline UM1WAnt & 0.177 & 0.117 & + \\
\hline UM2WAnt & 0.211 & 0.110 & + \\
\hline UP2L & -0.032 & 0.126 & \\
\hline UP3L & 0.010 & 0.109 & \\
\hline UP4L & 0.008 & 0.097 & \\
\hline UM1L & -0.022 & 0.143 & \\
\hline UM2L & 0.115 & 0.173 & \\
\hline UI1L & -0.215 & 0.128 & - \\
\hline $\mathrm{UI} 2 \mathrm{~L}$ & -0.133 & 0.110 & - \\
\hline $\mathrm{UC} 1 \mathrm{~L}$ & -0.006 & 0.148 & \\
\hline
\end{tabular}

LogEQs for extant anthropoids, relative to a baseline allometry for strepsirrhine primates, show that extant catarrhines and platyrrhines have relatively large brains. Both clades have similar distributions of $\operatorname{logEQs}$; catarrhine $\operatorname{logEQs}$ range from 1.39 to 2.25 (table 6: including hominoids, but not Homo sapiens), extant platyrrhines from 1.54 to 2.44 (table 6), and they are indistinguishable with a MannWhitney test $(\mathrm{U}=47, p>0.05)$. Although modern anthropoids possess large brains relative to body mass compared to other mammals (Radinsky, 1973, 1977; Martin, 1990), it is unclear whether this condition 
typifies Anthropoidea ancestrally, or whether, as Kay et al. (1997) have suggested, Catarrhini and Platyrrhini each evolved relatively large brains in parallel. Martin (1990) analyzed 25 living haplorhines (Anthropoidea plus tarsiers), demonstrating that living anthropoids are large-brained compared to strepsirrhine primates relative to a "basal insectivores" reference frame.

Tejedor et al. (2006) noted that the $\sim 16.4$ Ma cebine platyrrhine Killikaike blakei possesses a strongly vaulted frontal and large anterior cranial fossa, suggesting an expanded forebrain early in cebine evolutionary history. Only the anterior portion of the skull is preserved, thus a total brain volume cannot be estimated, although enlarged forebrains do correlate with relatively larger brains in cebines, suggesting that the brain of Killikaike was likely quite large. Contemporaneous European hominoids, however, lacked significantly expanded brains (Begun, 2002). Martin (1990) noted that several fossil haplorhines also had much smaller brains than their extant relatives, including early "tarsioids" and the early catarrhine Aegyptopithecus zeuxis (logEQs: 0.901.06, table 6). These fossil haplorhines have larger brains than expected relative to the strepsirrhine allometry, yet are below the smallest calculated $\operatorname{logEQ}$ value for extant anthropoids. The constrained weighted-average body mass model for Chilecebus (583 grams) yields a $\operatorname{logEQ}$ of 1.11 (table 6), which is comparable to encephalization values observed among contemporaneous haplorhines, but is lower than observed values in all extant anthropoids. The largest and smallest body mass estimates for Chilecebus from the reduced set of measurements, 1206 grams and 430 grams, yield $\operatorname{logEQs}$ of 0.62 and 1.32, respectively. Thus, only if the sole smallest reliable morphometric proxy (of 20 estimators) is correct for Chilecebus would its estimated encephalization even begin to approach the lower bound of observed logEQs among extant anthropoid species (table 6).

The $\log E \mathrm{Q}$ estimates for Chilecebus and Martin's (1990) data for Aegyptopithecus, imply that early taxa basal to Platyrrhini and Catarrhini (but postdating the divergence between these two clades) had smaller relative brain volumes than extant members of either clade, suggesting that the elevated encephalizations of crown-clade platyrrhines and crownclade catarrhines have been achieved convergently, pointing to a complex transformation in relative brain size within Anthropoidea. Martin's (1990) suggestion that tarsiers and their fossil allies may exhibit an independent evolutionary trend of increasing encephalization emphasizes this pattern of multiple independent acquisitions of large relative brain volume in Primates. If confirmed, this evolutionary pattern in Primates would mirror independent increases in encephalization observed across mammalian lineages (Jerison, 1970; Radinsky, 1971; Martin, 1984), and within subclades of Carnivora (Finarelli and Flynn, 2007; Finarelli, 2008) and the Cetacea (Marino et al., 2004). The convergent acquisition of higher degrees of encephalization in platyrrhines and catarrhines may yield insights into the evolutionary history of these features in other clades.

\section{CONCLUSIONS}

Morphometric body mass estimation methods were evaluated using a suite of 80 cranial, mandibular, and dental variables for 17 species of extant platyrrhine primates, spanning the range of body masses within this group. The accuracy with which each morphological variable predicts body mass was quantified using the likelihood fit of the regression to the observed body mass data, with a log-likelihood difference of 2 indicating significantly better predictive power of one variable over another with respect to the observed data.

The best cranial morphometric predictor of body mass in platyrrhines is mandibular length. Only one variable, pterygoid-zygomatic length, fell within $2 \mathrm{LnL}$ units of mandibular length, indicating no significant difference in the predictive power of these variables with respect to the body mass data. While the best predictors were osteological measurements, the distribution of rank fits between osteological and dental variables does not differ significantly, and, contrary to the conclusions of some previous studies, there was no consistent difference between the relative predictive ability of dental versus cranial osteological variables. Mandibular and lower 
TABLE 6

Mass, brain volumes, and calculated $\log \mathrm{EQ}$ values

Values relative to Martin's 1990 regression for strepsirrhine primates as a frame of reference. Fossil "tarsioids" and the fossil catarrhine Aegyptopithecus from Martin, 1990. Data for Chilecebus are from this study. Minimum, maximum, and median logEQs for the extant Platyrrhini and Catarrhini are given to the right.

\begin{tabular}{|c|c|c|c|c|c|c|c|}
\hline Species & Body Mass [g] & Brain Volume $[\mathrm{mL}]$ & Ref & $\log \mathrm{EQ}$ & Min & Median & $\operatorname{Max}$ \\
\hline Aegyptopithecus zeuxis & 6710.00 & 34.40 & Martin 1990, p 388 & 0.98 & & & \\
\hline Necrolemur antiquus & 233.00 & 3.80 & Martin 1990, p 388 & 1.06 & & & \\
\hline Tetonius homonculus & 74.00 & 1.50 & Martin 1990, p 388 & 0.91 & & & \\
\hline Rooneyia viejaensis & 782.00 & 7.40 & Martin 1990, p 388 & 0.90 & & & \\
\hline Chilecebus carrascoensis & 582.62 & 7.46 & & 1.11 & & & \\
\hline Platyrrhini (extant) & & & & & 1.54 & 1.96 & 2.44 \\
\hline Aotus trivigatus & 535.50 & 16.90 & Martin 1990, p 362 & 1.99 & & & \\
\hline Callicebus moloch & 854.70 & 18.30 & Martin 1990, p 362 & 1.75 & & & \\
\hline Saimiri sciureus & 743.20 & 23.60 & Martin 1990, p 362 & 2.10 & & & \\
\hline Cebus appella & 2500.00 & 76.20 & Martin 1990, p 362 & 2.44 & & & \\
\hline Lagothrix lagotricha & 6300.00 & 97.20 & Martin 1990, p 362 & 2.06 & & & \\
\hline Allouatta seniculus & 6145.50 & 60.30 & Martin 1990, p 362 & 1.60 & & & \\
\hline Callimico goeldii & 480.00 & 11.10 & Martin 1990, p 362 & 1.64 & & & \\
\hline Cebuella pygmaea & 125.00 & 6.10 & Martin 1990, p 362 & 1.96 & & & \\
\hline Callithrix jacchus & 292.00 & 7.20 & Martin 1990, p 362 & 1.54 & & & \\
\hline Catarrhini (extant) & & & & & 1.39 & 2.00 & 2.25 \\
\hline Miopithecus talapoin & 1250.00 & 39.00 & Martin 1990, p 362 & 2.25 & & & \\
\hline Cercopithecus ascanius & 3605.00 & 63.40 & Martin 1990, p 362 & 2.01 & & & \\
\hline Cercocebus albigena & 7758.00 & 96.90 & Martin 1990, p 362 & 1.91 & & & \\
\hline Macaca mulatta & 4600.00 & 83.00 & Martin 1990, p 362 & 2.11 & & & \\
\hline Papio anubis & 16650.00 & 177.00 & Martin 1990, p 362 & 2.00 & & & \\
\hline Theropithecus gelada & 21500.00 & 133.00 & Martin 1990, p 362 & 1.54 & & & \\
\hline Colobus badius & 8617.00 & 61.60 & Martin 1990, p 362 & 1.39 & & & \\
\hline Hylobates lar & 5422.00 & 99.90 & Martin 1990, p 362 & 2.19 & & & \\
\hline Symphalanges syndactylus & 10725.00 & 123.70 & Martin 1990, p 362 & 1.94 & & & \\
\hline Pongo pygmaeus & 55000.00 & 418.00 & Martin 1990, p 362 & 2.04 & & & \\
\hline Pan troglodytes & 45290.00 & 393.00 & Martin 1990, p 362 & 2.11 & & & \\
\hline Gorilla gorilla & 114450.00 & 465.00 & Martin 1990, p 362 & 1.65 & & & \\
\hline
\end{tabular}

dental measurements do correlate significantly better with body mass than those from the cranium and upper teeth.

Applying the 46 measurable body mass proxies to the cranium and upper dentition of the $20 \mathrm{Ma}$ platyrrhine Chilecebus yields a wide range of body mass estimates (85 grams to $\sim 1.7 \mathrm{~kg}$ ). An initial weighted-average model, applying the likelihood fits of each variable, produced a body mass estimate of 319 grams, considerably less than a previous preliminary report $(1.0-1.2 \mathrm{~kg}$ : Flynn et al., 1995). The wide range of body mass estimates for Chilecebus underscores the hazards of applying body mass proxies to early diverging fossil taxa with potentially novel morphometries. Compared to the extant platyrrhine regression, 26 proxies in Chilecebus differ significantly from the allometry observed among extant taxa. Importantly, variables that both significantly underestimate and overestimate body mass are among the proxies that are inconsistent with modern allometries. Applying the weighted-average model technique to a constrained set of only the 20 proxies that follow extant allometries yields the most reliable body mass estimate for Chilecebus: 583 grams.

Based on this 583 gram body mass estimate, the encephalization of Chilecebus ( $\log \mathrm{EQ}=$ 1.11) was found to be lower than that of all living anthropoid primates. This EQ is comparable to that of the early catarrhine Aegyptopithecus, indicating that the high 
degree of encephalization observed among modern anthropoids likely was attained independently in both the platyrrhine and catarrhine clades.

\section{ACKNOWLEDGMENTS}

This research was supported by our home institutions, research grants from the U.S. National Science Foundation (DEB-9317943, DEB-0317014 and DEB-0513476 to JJF; DEB-9020213 and DEB-9318126 to ARW), a John S. Guggenheim Memorial Foundation Fellowship (JJF), fellowships from the University of Chicago and Field Museum (KES, JAF), and by the University of Michigan, Society of Fellows (JAF). We thank the staff of the Field Museum Division of Mammalogy and the Mammalogy Collections of the American Museum of Natural History for access to extant primate specimens. We are grateful for the long-term support of the Museo Nacional de Historia Natural (Santiago, Chile) and the Consejo Nacional de Monumentos Naturales de Chile. We especially acknowledge the exceptional preparation talents and efforts of our deceased friend and colleague, Steven McCarroll, who painstakingly removed the skull of Chilecebus from its extremely hard volcaniclastic matrix.

\section{REFERENCES}

Anthony, M.R.L., and R.F. Kay. 1993. Tooth form and diet in ateline and alouattine Primates: reflections on the comparative method. American Journal of Science 293: 356-382.

Begun, D.R. 2002. European hominoids. In W.C. Hartwig (editor), The primate fossil record, 339-368. Cambridge: Cambridge University Press.

Bouvier, M. 1986. Biomechanical scaling of mandibular dimensions in New World monkeys. International Journal of Primatology 7: 551-567.

Burnham, K.P., and D.R. Anderson. 2002. Model selection and multimodel inference: a practical information-theoretic approach. New York: Springer, $488 \mathrm{pp}$.

Canavez, F.C., M.A.M. Moreira, J.J. Ladasky, A. Pissinatti, P. Parham, and H.N. Seuanez. 1999. Molecular phylogeny of New World primates (Platyrrhini) based on beta(2)-microglobulin
DNA sequences. Molecular Phylogenetics and Evolution 12: 74-82.

Conroy, G.C. 1987. Problems of body weight estimation in fossil primates. International Journal of Primatology 8: 115-138.

Coombs, M.C. 1975. Sexual dimorphism in chalicotheres (Mammalia, Perissodactyla). Systematic Zoology 24: 55-62.

Dagosto, M., and C.J. Terranova. 1992. Estimating the body size of Eocene primates: a comparison of results from dental and postcranial variables. International Journal of Primatology 13: 307-344.

Damuth, J. 1987. Interspecific allometry of population density in mammals and other animals: the independence of body mass and population energy use. Biological Journal of the Linnean Society 31: 193-246.

Damuth, J., and B.J. MacFadden. 1990. Introduction: body size and its estimation. In J. Damuth and B.J. MacFadden (editors), Body size in mammalian paleobiology, 1-9. New York: Cambridge University Press.

Delson, E., C.J. Terranova, W.L. Jungers, E.J. Sargis, N.G. Jablonski, and P.C. Dechow. 2000. Body mass in Cercopithecidae (Primates, Mammalia): estimation and scaling in extinct and extant taxa. Anthropological Papers of the American Museum of Natural History 83: $1-159$.

Eaglen, R.H. 1984. Incisor size and diet revisited: the view from a platyrrhine perspective. American Journal of Physical Anthropology 64: 263-275.

Edwards, A.W.F. 1992. Likelihood. Expanded ed. Baltimore, MD: Johns Hopkins University Press, 296 pp.

Eisenberg, J.F. 1990. The behavioral/ecological significance of body size in the Mammalia. In J. Damuth and B.J. MacFadden (editors), Body size in mammalian paleobiology, 25-37. New York: Cambridge University Press.

Felsenstein, J. 1985. Phylogenies and the comparative method. American Naturalist 125: 1-15.

Finarelli, J.A. 2008. Testing hypotheses of the evolution of brain-body size scaling in the Canidae (Carnivora, Mammalia). Paleobiology 34: 48-58.

Finarelli, J.A., and J.J. Flynn. 2006. Ancestral state reconstruction of body size in the Caniformia (Carnivora, Mammalia): the effects of incorporating data from the fossil record. Systematic Biology 55: 301-313.

Finarelli, J.A., and J.J. Flynn. 2007. The evolution of encephalization in caniform carnivorans. Evolution 61: 1758-1772.

Fleagle, J.G., R.F. Kay, and E.L. Simons. 1980. Sexual dimorphism in early anthropoids. Nature 287: 328-330. 
Flynn, J.J., A.R. Wyss, R. Charrier, and C.C. Swisher. 1995. An early Miocene anthropoid skull from the Chilean Andes. Nature 373: 603-607.

Garland, T., and A.R. Ives. 2000. Using the past to predict the present: confidence intervals for regression equations in phylogenetic comparative methods. American Naturalist 155: 346-364.

Gillooly, J.F., A.P. Allen, G.B. West, and J.H. Brown. 2005. The rate of DNA evolution: effects of body size and temperature on the molecular clock. Proceedings of the National Academy of Sciences of the United States of America 102: 140-145.

Gingerich, P.D. 1974. Size variability of the teeth in living mammals and the diagnosis of closely related sympatric species. Journal of Paleontology 48: 895-903.

Gingerich, P.D. 1990. Prediction of body mass in mammalian species from long bone lengths and diameters. In Contributions from the Museum of Paleontology University of Michigan 28: 79-92.

Gingerich, P.D., and M.J. Schoeninger. 1979. Patterns of tooth size variability in the dentition of primates. American Journal of Physical Anthropology 51: 457-466.

Gingerich, P.D., and H.B. Smith. 1984. Allometric scaling in the dentition of primates and insectivores. In W.L. Jungers (editor), Size and scaling in primate biology, 257-272. New York: Plenum.

Gingerich, P.D., H.B. Smith, and K. Rosenberg. 1982. Allometric scaling in the dentition of Primates and prediction of body weight from tooth size in fossils. American Journal of Physical Anthropology 58: 81-100.

Gittleman, J.L. 1986. Carnivore life history patterns: allometric, phylogenetic, and ecological associations. American Naturalist 127: 744 771.

Gittleman, J.L. 1991. Carnivore olfactory bulb size: allometry, phylogeny and ecology. Journal of Zoology 225: 253-272.

Gittleman, J.L. 1993. Carnivore life histories: a reanalysis in light of new models. In $\mathrm{N}$. Dunstone and M. Gorman (editors), Mammals as predators: the proceedings of a symposium held by the Zoological Society of London and the Mammal Society, London, 22nd and 23rd November 1991: 65-86. New York: Clarendon Press.

Gittleman, J.L., and P.H. Harvey. 1982. Carnivore home-range size, metabolic needs and ecology. Behavioral Ecology and Sociobiology 10: 57-63.
Hartwig, W.C. 1993. Comparative morphology, ontogeny and phylogenetic analysis of the platyrrhine cranium. Ph.D. dissertation, University of California: Berkeley, $629 \mathrm{pp}$.

Hills, M., and B.A. Wood. 1984. Regression lines, size and allometry. In D.J. Chivers, B.A. Wood and A. Bilsborough (editors), Food acquisition and processing in primates, 557-567. New York: Plenum Press.

Janis, C.M., M.W. Colbert, M.C. Coombs, W.D. Lambert, B.J. MacFadden, B.J. Mader, D.R. Prothero, R.M. Schoch, J. Shoshani, and W.P. Wall. 1998a. Perissodactyla and Probosciedea. In C.M. Janis, K.M. Scott and L.L. Jacobs (editors), Evolution of Tertiary mammals of North America, 511-524. New York: Cambridge University Press.

Janis, C.M., J.A. Effinger, J.A. Harrison, J.G. Honey, D.G. Kron, B. Lander, E. Manning, D.R. Prothero, M.S. Stevens, R.K. Stucky, D. Webb, and D.B. Wright. 1998b. Artiodactyla. In C.M. Janis, K.M. Scott and L.L. Jacobs (editors), Evolution of Tertiary mammals of North America, 337-357. New York: Cambridge University Press.

Jerison, H. 1970. Brain evolution: new light on old principles. Science 170: 1224-1225.

Jungers, W.L. 1990. Problems and methods in reconstructing body size in fossil Primates. In J. Damuth and B.J. MacFadden (editors), Body size in mammalian paleobiology, 103-118. New York: Cambridge University Press.

Kay, R.F., and E.L. Simons. 1980. Ecology of Oligocene African Anthropoidea. American Journal of Physical Anthropology 50: 453-453.

Kay, R.F., C. Ross, and B.A. Williams. 1997. Anthropoid origins. Science 275: 797-804.

Kobayashi, S. 1995. A phylogenetic study of titi monkeys, genus Callicebus, based on cranial measurements. Primates 36: 101-120.

Krishtalka, L., R.K. Stucky, and K.C. Beard. 1990. The earliest fossil evidence for sexual dimorphism in primates. Proceedings of the National Academy of Sciences of the United States of America 87: 5223-5226.

Legendre, S. 1986. Analysis of mammalian communities from the late Eocene and Oligocene of southern France. Palaeovertebrata 16: 191-212.

Legendre, S., and C. Roth. 1988. Correlation of carnassial tooth size and body weight in Recent carnivores (Mammalia). Historical Biology 1: 85-98.

Maddison, W.P., and D.R. Maddison. 2004. Mesquite: a modular system for evolutionary analysis. Available from http://mesquiteproject. $\mathrm{org} / \mathrm{mesquite} / \mathrm{mesquite}$.html.

Maddison, W.P., D.R. Maddison, and P. Midford. 2002. TreeFarm: a package of modules for 
Mesquite. Available from http://mesquiteproject. org/mesquite/mesquite.html.

Marino, L., D.W. McShea, and M.D. Uhen. 2004. Origin and evolution of large brains in toothed whales: anatomical record. Part a. Discoveries in Molecular Cellular and Evolutionary Biology 281A: 1247-1255.

Martin, R.D. 1984. Body size, brain size and feeding strategies. In D.J. Chivers, B.A. Wood and A. Bilsborough (editors), Food acquisition and processing in primates, $73-104$. New York: Plenum Press.

Martin, R.D. 1990. Primate origins and evolution: a phylogenetic reconstruction. London: Chapman and Hall, 840 pp.

Martin, R.D., L.A. Willner, and A. Dettling. 1994. The evolution of sexual dimorphism in primates. In R.V. Short and E. Balaban (editors), The differences between the sexes, 159-200. Cambridge: Cambridge University Press.

McNab, B.K., and J.F. Eisenberg. 1989. Brain size and its relation to the rate of metabolism in mammals. American Naturalist 133: 157-167.

Midford, P., T. Garland, and W.P. Maddison. 2003. PDAP package (of Mesquite). Available from http://mesquiteproject.org/mesquite/mesquite. html.

Radinsky, L.B. 1971. An example of parallelism in carnivore brain evolution. Evolution 25: $518-522$.

Radinsky, L.B. 1973. Aegyptopithecus endocasts: oldest records of a pongid brain. American Journal of Physical Anthropology 39: 239-247.

Radinsky, L.B. 1977. Early primate brains: facts and fiction. Journal of Human Evolution 6: 79-86.

Radinsky, L.B. 1981a. Evolution of skull shape in carnivores. 1. Biological Journal of the Linean Society 15: 369-388.

Radinsky, L.B. 1981b. Evolution of skull shape in carnivores. 2. Biological Journal of the Linnean Society 16: 337-355.

Radinsky, L.B. 1982. Evolution in skull shape in carnivores. 3. Paleobiology 8: 177-195.

Rensch, B. 1950. Die Abhängigkeit der relativen Sexualdifferenz von der Körpergrösse. Bonner Zoologische Beiträge 1: 58-69.

Royall, R.M. 1997. Statistical evidence: a likelihood paradigm. New York: Chapman and Hall, $191 \mathrm{pp}$.

Ruff, C. 1990. Body mass and hindlimb bone crosssectional and articular dimensions in anthro- poid primates. In J. Damuth and B.J. MacFadden (editors), Body size in mammalian paleobiology, 119-149. New York: Cambridge University Press.

Schmidt-Nielsen, K. 1984. Scaling: why is animal size so important? Cambridge: Cambridge University Press, 239 pp.

Simons, E.L. 1993. New endocasts of Aegyptopithecus: oldest well-preserved record of the brain in Anthropoidea. American Journal of Science 293A: 383-390.

Smith, F.A., S.K. Lyons, S.K.M. Ernest, K.E. Jones, D.M. Kaufman, T. Dayan, P.A. Marquet, J.H. Brown, and J.P. Haskell. 2003. Body mass of late Quaternary mammals. Ecology 84: 3403.

Sokal, R.R., and F.J. Rohlf. 1995. Biometry: the principles and practice of statistic in biological research. New York: W. H. Freeman, 887 pp.

Spocter, M.A., and P.R. Manger. 2007. The use of cranial variables for the estimation of body mass in fossil hominins. American Journal of Physical Anthropology 134: 92-105.

Tejedor, M.F., A.A. Tauber, A.L. Rosenberger, C.C. Swisher, and M.E. Palacios. 2006. New primate genus from the Miocene of Argentina. Proceedings of the National Academy of Sciences of the United States of America 103: 5437-5441.

Van Valkenburgh, B. 1990. Skeletal and dental predictors of body mass in carnivores. In $\mathrm{J}$. Damuth and B.J. MacFadden (editors), Body size in mammalian paleobiology, 181-206. New York: Cambridge University Press.

Van Valkenburgh, B., and T. Sacco. 2002. Sexual dimorphism, social behavior, and intrasexual competition in large Pleistocene carnivorans. Journal of Vertebrate Paleontology 22: 164-169.

von Dornum, M., and M. Ruvolo. 1999. Phylogenetic relationships of the New World monkeys (Primates, Platyrrhini) based on nuclear G6PD DNA sequences. Molecular Phylogenetics and Evolution 11: 459-476.

Wagner, P.J. 2000a. Likelihood tests of hypothesized durations: determining and accommodating biasing factors. Paleobiology 26: 431-449.

Wagner, P.J. 2000b. The quality of the fossil record and the accuracy of phylogenetic inferences about sampling and diversity. Systematic Biology 49: 65-86. 


\section{APPENDIX 1 \\ Measurement Variables}

\begin{tabular}{|c|c|c|}
\hline Location & Measurement Name & Description \\
\hline \multirow[t]{12}{*}{ Craniallventral } & Skull length & from the back of the occiput to the anterior tip of the premaxilla \\
\hline & Occipital width & across the mastoids at the widest part of the occiput \\
\hline & Condyle length & $\begin{array}{l}\text { at the longest part of the condyle, from the most posterior to the } \\
\text { most anterior point along the condyle plane }\end{array}$ \\
\hline & Condyle width & $\begin{array}{l}\text { at the widest part of the condyle, along the lateral axis, } \\
\text { perpendicular to measurement condyle length }\end{array}$ \\
\hline & Foramen magnum height & along the anterior-posterior axis of the skull \\
\hline & Foramen magnum width & measured perpendicular to measurement foramen magnum height \\
\hline & Foramen magnum area & product of length and width measurements \\
\hline & Basal length of pterygoid fossa & $\begin{array}{l}\text { distance between sphenobasin and the base, or upper part of } \\
\text { contact, of the vomer }\end{array}$ \\
\hline & Pterygoid-zygomatic length & $\begin{array}{l}\text { from the posterior base of the pterygoid plate to the most } \\
\text { posterior point of zygomatic skull attachment }\end{array}$ \\
\hline & Bulla length & at longest part of bulla, at oblique angle to the midline of the skull \\
\hline & Bulla width & at widest part of bulla \\
\hline & Occipital chord & chord from the lambda to the opisthion \\
\hline \multirow[t]{8}{*}{ Cranialldorsal } & Braincase width & at widest part of braincase \\
\hline & Temporal fossa length & $\begin{array}{l}\text { from the most posterior point of the lamboidal crest to the back } \\
\text { of the supraorbital process }\end{array}$ \\
\hline & Postorbital constriction & at narrowest point posterior to orbits \\
\hline & Bizygomatic & across the widest portion of the zygomatic arches \\
\hline & Braincase length & from the postorbital constriction to the occipital condyles \\
\hline & Width of infratemporal fossa & $\begin{array}{l}\text { from parietal-sphenoid-temporal junction to anterosuperior } \\
\text { zygomatic-temporal suture }\end{array}$ \\
\hline & Frontal chord & from bregma to nasion \\
\hline & Parietal chord & from bregma to lambda \\
\hline Craniallposterior & Skull vault height & from top of skull (highest point) to condyles \\
\hline \multirow{3}{*}{ Craniallanterior } & Orbit width & at widest part of the orbit \\
\hline & Facial height (length) & $\begin{array}{l}\text { along bony midline from nasion to acanthion, or uppermost } \\
\text { midline point of the premaxilla }\end{array}$ \\
\hline & Vertical face height & $\begin{array}{l}\text { from the line between nasion and intersection of the } \\
\text { intermaxillary and interpalatine sutures on the hard palate }\end{array}$ \\
\hline Cranial/lateral & Temporal chord & from the bregma on top of the skull to the asterion \\
\hline \multirow[t]{5}{*}{ Mandibular } & Mandibular length & $\begin{array}{l}\text { from the back of the condyle to the front of the median incisor } \\
\text { alveolus }\end{array}$ \\
\hline & Mandibular height & from ventral base of the ramus to the base of the tooth \\
\hline & Moment arm of the masseter & $\begin{array}{l}\text { from dorsal surface of the condyle to central border of the angular } \\
\text { process }\end{array}$ \\
\hline & Moment arm of the temporalis & from posterior point to most anterior point of masseteric fossa \\
\hline & Masseteric fossa length & $\begin{array}{l}\text { from back of the condyle to most anterior point of the masseteric } \\
\text { fossa }\end{array}$ \\
\hline \multirow[t]{2}{*}{ Palate } & Palate length & $\begin{array}{l}\text { from most posterior point of tooth row to most anterior point of } \\
\text { maxilla }\end{array}$ \\
\hline & Palate width & chord across palate at M1 \\
\hline \multirow[t]{7}{*}{ Dental } & $\begin{array}{l}\text { Cheek tooth row } \\
\text { (upper and lower) }\end{array}$ & length of all premolars and molars \\
\hline & Width of all teeth & at the widest part of tooth: $\mathrm{I} 1, \mathrm{I} 2, \mathrm{C} 1, \mathrm{P} 2, \mathrm{P} 3, \mathrm{P} 4$ \\
\hline & (upper and lower) & width of anterior and posterior lophs: M1,M2 \\
\hline & $\begin{array}{l}\text { Length of all teeth } \\
\quad \text { (upper and lower) }\end{array}$ & mesiodistal length of: I1,I2,C1,P2,P3,P4,M1,M2 \\
\hline & Area of cheek teeth & product of length and width: $\mathrm{P} 2, \mathrm{P} 3, \mathrm{P} 4$ \\
\hline & (upper and lower) & average of width measurements for: M1,M2 \\
\hline & Maxillary incisor size & $\begin{array}{l}\text { chord between the distal cemento-enamel junction of the left and } \\
\text { right lateral incisors }\end{array}$ \\
\hline
\end{tabular}


APPENDIX 2

Platyrrhine Specimens Examined

\begin{tabular}{|c|c|c|c|c|c|c|c|}
\hline Species & $\mathrm{n}$ & Specimen & Sex & Species & $\mathrm{n}$ & Specimen & Sex \\
\hline \multirow[t]{9}{*}{ Alouatta caraya } & 8 & FMNH 96012 & $\mathrm{M}$ & Callithrix pygmaea & 10 & AMNH 76327 & $\mathrm{M}$ \\
\hline & & FMNH 96013 & M & & & AMNH 239605 & M \\
\hline & & FMNH 26560 & M & & & AMNH 182942 & M \\
\hline & & FMNH 26568 & M & & & AMNH 182943 & M \\
\hline & & FMNH 96011 & $\mathrm{~F}$ & & & AMNH 75280 & M \\
\hline & & FMNH 26555 & $\mathrm{~F}$ & & & AMNH 74056 & $\mathrm{~F}$ \\
\hline & & FMNH 26559 & $\mathrm{~F}$ & & & AMNH 74371 & $\mathrm{~F}$ \\
\hline & & FMNH 26569 & $\mathrm{~F}$ & & & AMNH 73751 & $\mathrm{~F}$ \\
\hline & & & & & & AMNH 74369 & $\mathrm{~F}$ \\
\hline \multirow[t]{11}{*}{ Aotus vociferans } & 10 & FMNH 70682 & M & & & AMNH 182944 & $\mathrm{~F}$ \\
\hline & & FMNH 70685 & M & & & & \\
\hline & & FMNH 70688 & M & Cebus apella & 10 & FMNH 92111 & M \\
\hline & & FMNH 70690 & M & & & FMNH 92114 & $\mathrm{M}$ \\
\hline & & FMNH 54293 & M & & & FMNH 92115 & M \\
\hline & & FMNH 70681 & $\mathrm{~F}$ & & & FMNH 92116 & M \\
\hline & & FMNH 70683 & $\mathrm{~F}$ & & & FMNH 92120 & M \\
\hline & & FMNH 70684 & $\mathrm{~F}$ & & & FMNH 92112 & $\mathrm{~F}$ \\
\hline & & FMNH 70686 & $\mathrm{~F}$ & & & FMNH 92113 & $\mathrm{~F}$ \\
\hline & & FMNH 70687 & $\mathrm{~F}$ & & & FMNH 92117 & $\mathrm{~F}$ \\
\hline & & & & & & FMNH 92118 & $\mathrm{~F}$ \\
\hline \multirow[t]{11}{*}{ Ateles geoffroyi } & 10 & FMNH 41584 & M & & & FMNH 92119 & $\mathrm{~F}$ \\
\hline & & FMNH 13896 & M & & & & \\
\hline & & FMNH 13897 & M & Chiropotes satanas & 10 & FMNH 95518 & M \\
\hline & & FMNH 13898 & M & & & FMNH 95519 & $\mathrm{M}$ \\
\hline & & FMNH 13899 & M & & & FMNH 93255 & $\mathrm{M}$ \\
\hline & & FMNH 66940 & $\mathrm{~F}$ & & & FMNH 95513 & $\mathrm{M}$ \\
\hline & & FMNH 66941 & $\mathrm{~F}$ & & & FMNH 95512 & $\mathrm{M}$ \\
\hline & & FMNH 13902 & $\mathrm{~F}$ & & & FMNH 93254 & $\mathrm{~F}$ \\
\hline & & FMNH 13903 & $\mathrm{~F}$ & & & FMNH 93522 & $\mathrm{~F}$ \\
\hline & & FMNH 49336 & $\mathrm{~F}$ & & & FMNH 95514 & $\mathrm{~F}$ \\
\hline & & & & & & FMNH 95515 & $\mathrm{~F}$ \\
\hline \multirow[t]{3}{*}{ Brachyteles arachnoides } & 2 & AMNH 80405 & $\mathrm{~F}$ & & & FMNH 95516 & $\mathrm{~F}$ \\
\hline & & AMNH 128 & $?$ & & & & \\
\hline & & & & Lagothrix lagotricha & 10 & FMNH 70574 & $\mathrm{M}$ \\
\hline \multirow[t]{11}{*}{ Cacajao calvus } & 10 & AMNH 70191 & M & & & FMNH 70575 & $\mathrm{M}$ \\
\hline & & AMNH 73717 & M & & & FMNH 70576 & M \\
\hline & & AMNH 73718 & $\mathrm{M}$ & & & FMNH 70577 & $\mathrm{M}$ \\
\hline & & AMNH 73716 & M & & & FMNH 70578 & $\mathrm{M}$ \\
\hline & & AMNH 98316 & M & & & FMNH 70581 & $\mathrm{~F}$ \\
\hline & & AMNH 76392 & M & & & FMNH 70582 & $\mathrm{~F}$ \\
\hline & & AMNH73719 & $\mathrm{F}$ & & & FMNH 70583 & $\mathrm{~F}$ \\
\hline & & AMNH 98397 & $\mathrm{~F}$ & & & FMNH 70584 & $\mathrm{~F}$ \\
\hline & & AMMH 76390 & $\mathrm{~F}$ & & & FMNH 70589 & $\mathrm{~F}$ \\
\hline & & AMNH 76649 & $\mathrm{~F}$ & & & & \\
\hline & & & & $\begin{array}{l}\text { Leontopithecus } \\
\quad \text { rosalia }\end{array}$ & 10 & FMNH 122012 & M \\
\hline \multirow[t]{6}{*}{ Cacajao melanocephalus } & 6 & AMNH 78562 & M & & & FMNH 57150 & M \\
\hline & & AMNH 78566 & M & & & FMNH 57586 & $\mathrm{M}$ \\
\hline & & AMNH 78567 & M & & & FMNH 57838 & M \\
\hline & & AMNH 78569 & $\mathrm{~F}$ & & & FMNH 57839 & $\mathrm{M}$ \\
\hline & & AMNH 78568 & $\mathrm{~F}$ & & & FMNH 63769 & $\mathrm{~F}$ \\
\hline & & AMNH 78571 & $\mathrm{~F}$ & & & FMNH 48356 & $\mathrm{~F}$ \\
\hline
\end{tabular}


APPENDIX 2

(Continued)

\begin{tabular}{|c|c|c|c|c|c|c|c|}
\hline Species & $\mathrm{n}$ & Specimen & Sex & Species & $\mathrm{n}$ & Specimen & Sex \\
\hline \multirow{13}{*}{ Callimico goeldii } & \multirow{13}{*}{11} & & & \multirow{13}{*}{ Pithecia pithecia } & \multirow{13}{*}{10} & FMNH 57152 & $\mathrm{~F}$ \\
\hline & & FMNH 148062 & $\mathrm{M}$ & & & FMNH 57998 & $\mathrm{~F}$ \\
\hline & & FMNH 148065 & $\mathrm{M}$ & & & FMNH 134505 & F \\
\hline & & FMNH 145462 & M & & & & \\
\hline & & FMNH 153715 & M & & & FMNH 93251 & M \\
\hline & & AMNH 183290 & $\mathrm{~F}$ & & & FMNH 93252 & M \\
\hline & & FMNH 153712 & $\mathrm{~F}$ & & & FMNH 95508 & M \\
\hline & & FMNH 159976 & $\mathrm{~F}$ & & & FMNH 95509 & $\mathrm{M}$ \\
\hline & & FMNH 159975 & $\mathrm{~F}$ & & & FMNH 95504 & $\mathrm{M}$ \\
\hline & & FMNH 150674 & $\mathrm{~F}$ & & & FMNH 93250 & $\mathrm{~F}$ \\
\hline & & AMNH 239601 & $?$ & & & FMNH 93253 & $\mathrm{~F}$ \\
\hline & & AMNH 176602 & ? & & & FMNH 95510 & $\mathrm{~F}$ \\
\hline & & & & & & FMNH 95511 & $\mathrm{~F}$ \\
\hline \multirow[t]{11}{*}{ Callithrix jacchus } & \multirow[t]{11}{*}{10} & FMNH 20420 & $\mathrm{M}$ & & & FMNH 95506 & $\mathrm{~F}$ \\
\hline & & FMNH 20228 & M & & & & \\
\hline & & FMNH 20229 & M & \multirow[t]{9}{*}{ Saguinas mystax } & \multirow[t]{9}{*}{10} & FMNH 86951 & M \\
\hline & & FMNH 20420 & M & & & FMNH 86952 & M \\
\hline & & FMNH 20736 & M & & & FMNH 86953 & M \\
\hline & & FMNH 20419 & $\mathrm{~F}$ & & & FMNH 86954 & M \\
\hline & & FMNH 20227 & F & & & FMNH 86955 & M \\
\hline & & FMNH 20419 & $\mathrm{~F}$ & & & FMNH 86959 & $\mathrm{~F}$ \\
\hline & & FMNH 20737 & F & & & FMNH 86960 & $\mathrm{~F}$ \\
\hline & & FMNH 20739 & $\mathrm{~F}$ & & & FMNH 86961 & $\mathrm{~F}$ \\
\hline & & & & & & FMNH 87138 & $\mathrm{~F}$ \\
\hline \multirow[t]{12}{*}{ Callicebus moloch } & \multirow[t]{12}{*}{10} & FMNH 92100 & $\mathrm{M}$ & & & FMNH 87139 & $\mathrm{~F}$ \\
\hline & & FMNH 92101 & $\mathrm{M}$ & & & & \\
\hline & & FMNH 92102 & M & \multirow[t]{10}{*}{ Saimiri sciureus } & \multirow[t]{10}{*}{10} & FMNH 70647 & M \\
\hline & & FMNH 92109 & M & & & FMNH 70650 & M \\
\hline & & FMNH 60749 & M & & & FMNH 70651 & M \\
\hline & & FMNH 48934 & $\mathrm{~F}$ & & & FMNH 70652 & M \\
\hline & & FMNH 50872 & F & & & FMNH 70655 & M \\
\hline & & FMNH 92103 & $\mathrm{~F}$ & & & FMNH 70643 & $\mathrm{~F}$ \\
\hline & & FMNH 92104 & F & & & FMNH 70644 & $\mathrm{~F}$ \\
\hline & & FMNH 92105 & $\mathrm{~F}$ & & & FMNH 70645 & F \\
\hline & & & & & & FMNH 70646 & $\mathrm{~F}$ \\
\hline & & & & & & FMNH 70648 & $\mathrm{~F}$ \\
\hline
\end{tabular}

\footnotetext{
Specimen numbers are for Field Museum of Natural History (FMNH) and American Museum of Natural History
} (AMNH) mammalogy collections. 


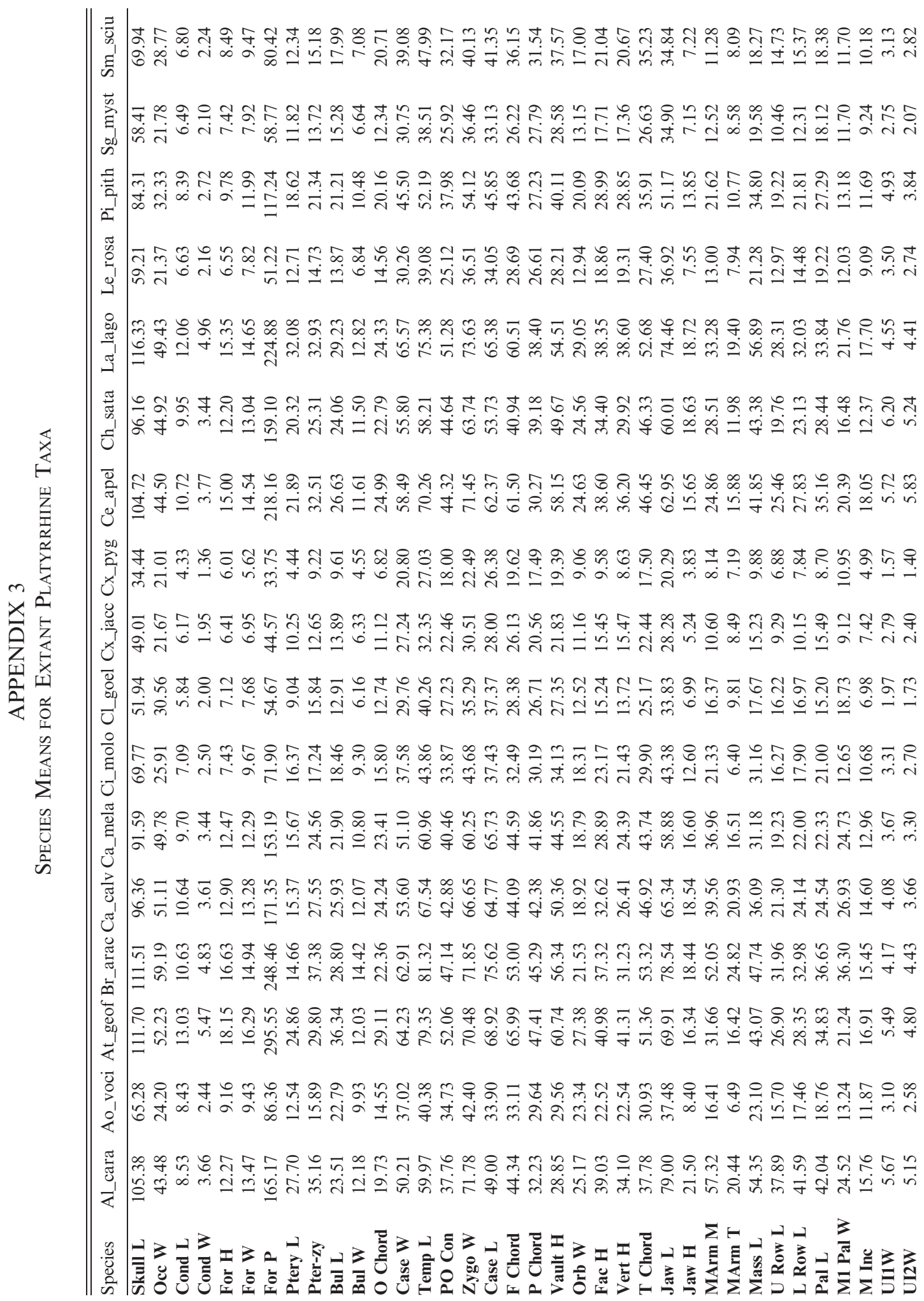




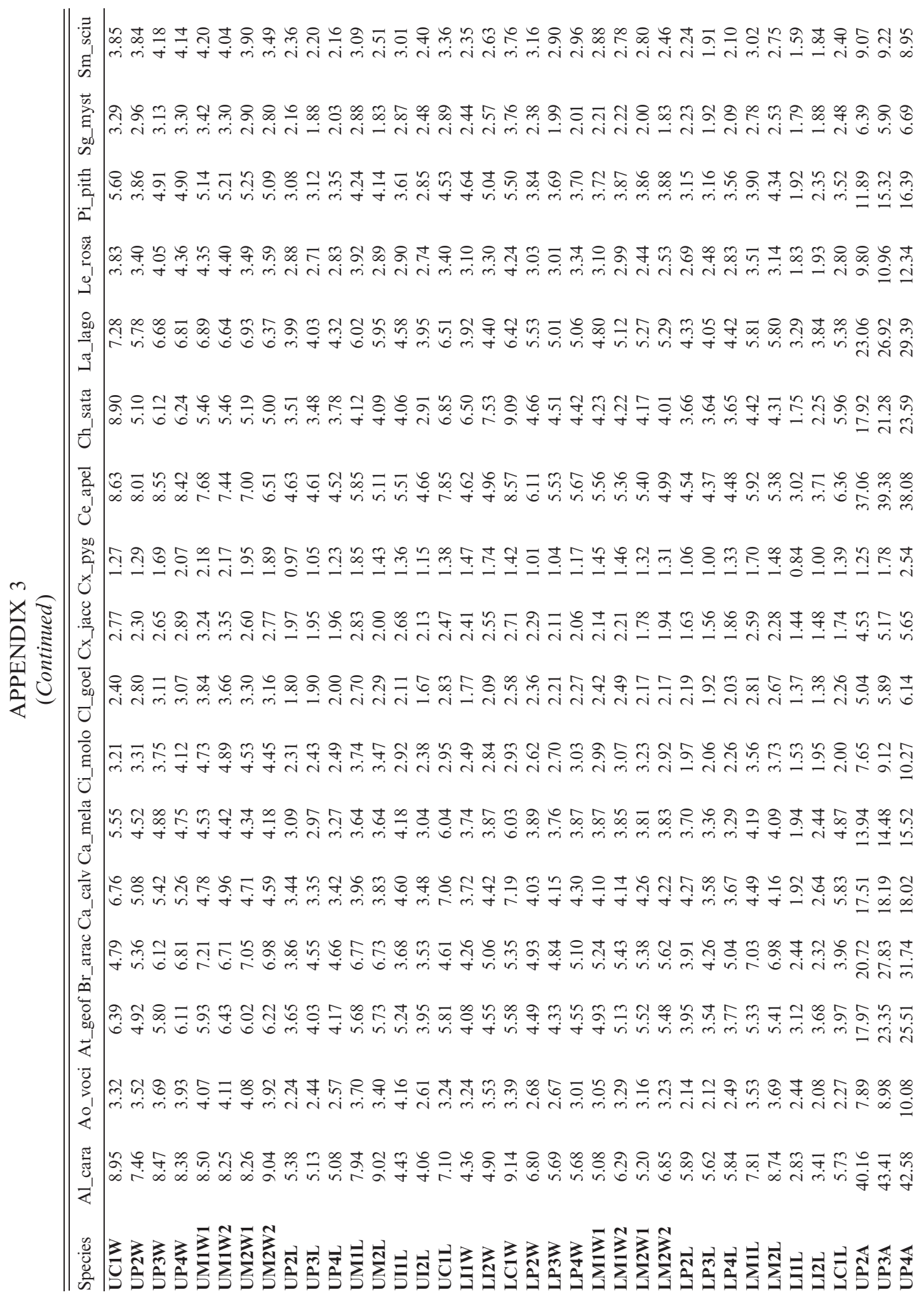




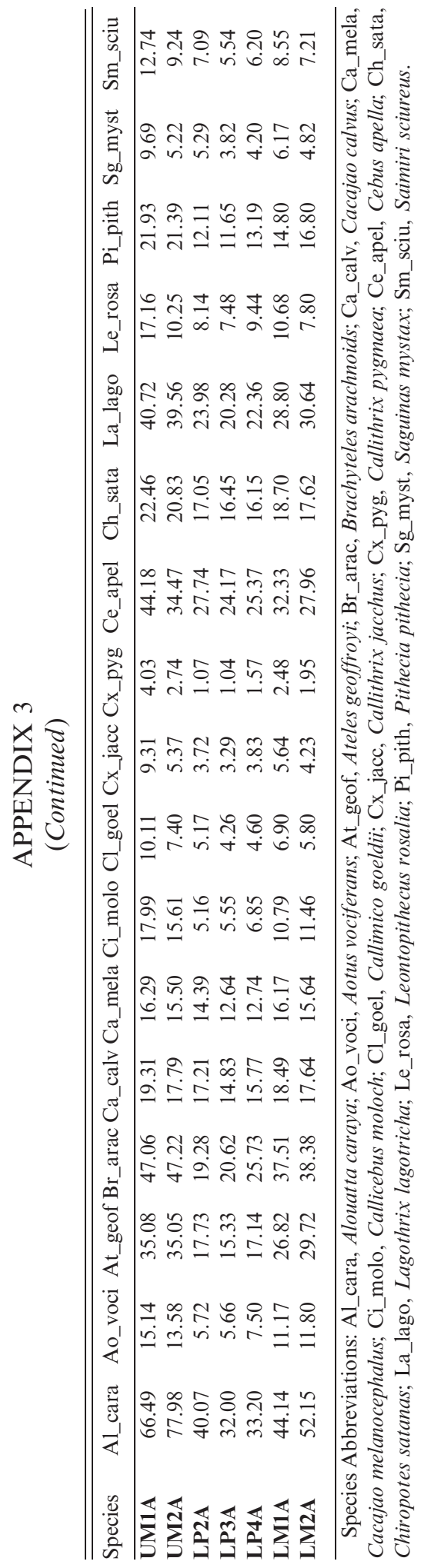


APPENDIX 4

Scatterplots of Regressions of Body Mass on Measurement Variables

$\mathrm{Y}$-axis is body mass in all plots, $\mathrm{X}$-axis variable indicated in each plot. Plots are phylogenetically independent contrasts.

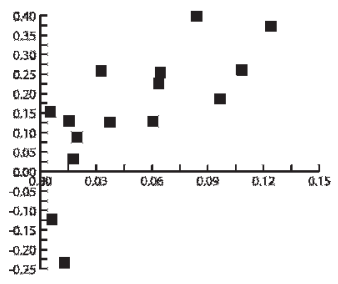

5kwll Length

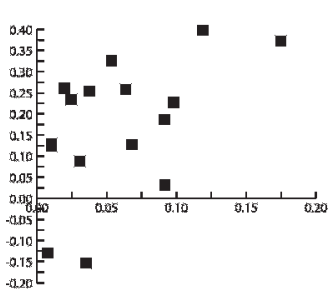

Foramen Magnum Height

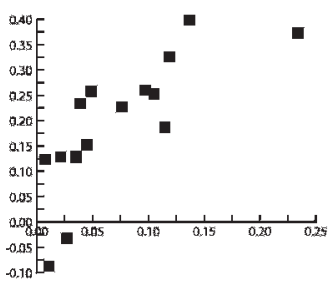

Pterygoid-Zygomatic Length

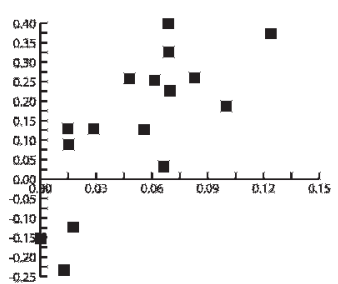

Braincase Width

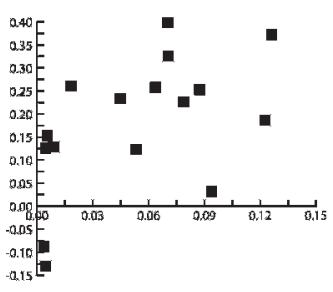

Braincase Length

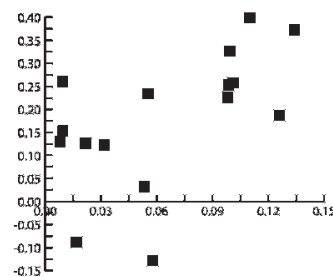

Occipital Width

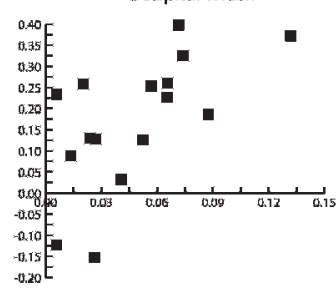

Foramen Magmum Width

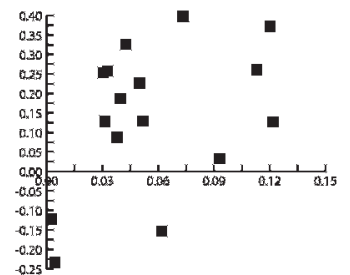

Bullar Length

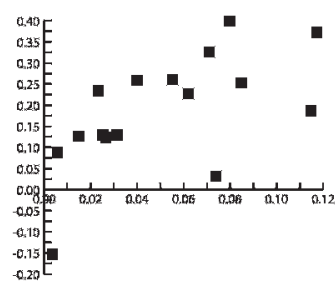

Temporalis Length

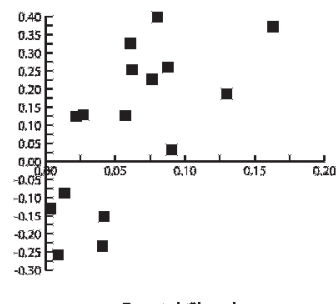

Frontal Chord

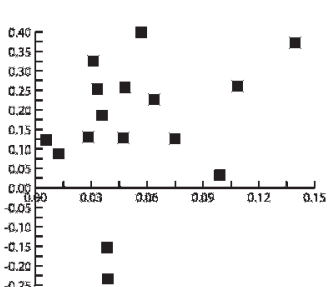

Condyle Length

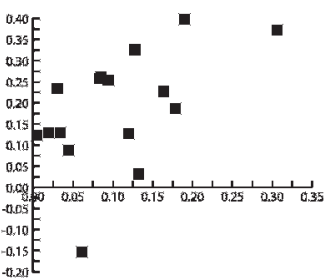

Foramen Magnum Area

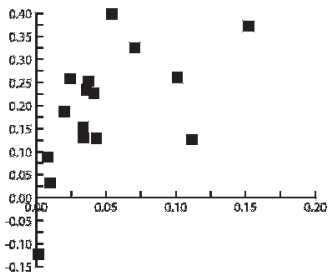

Bullar Width

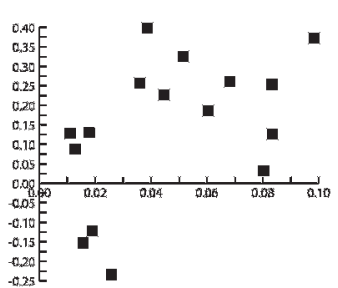

Post-Orbital Constriction Width

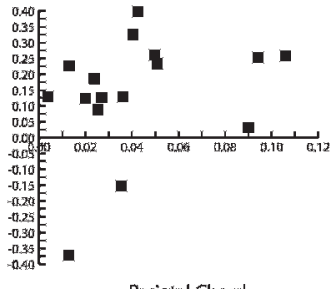

Parietal Chord

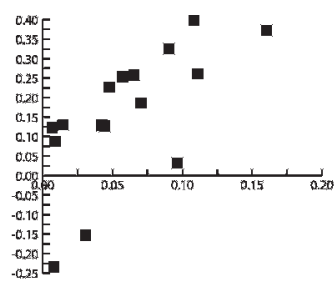

Condyle Width

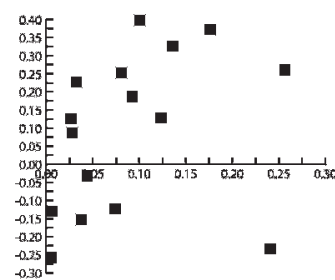

Length of Pterygoid Fossa

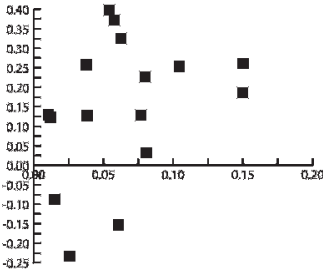

Occipital Chord

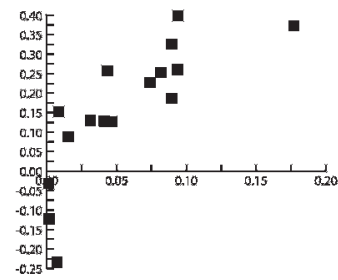

Bi-Zygomatîc Width

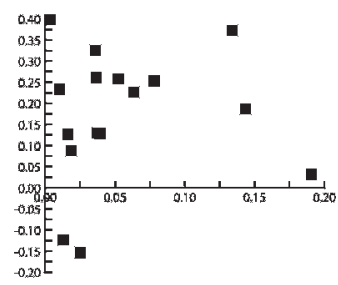

Braincase Height 


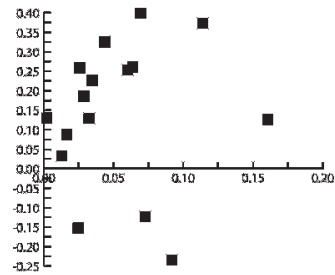

Orbital Width

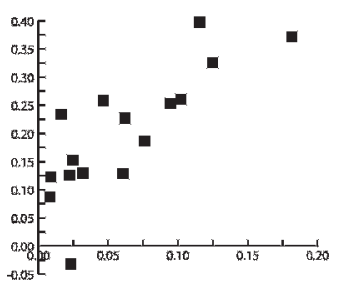

Mandibular Length

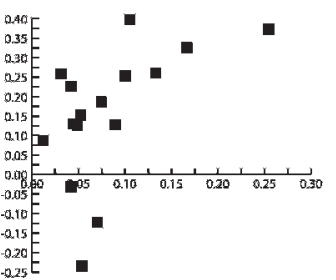

Masseter Length

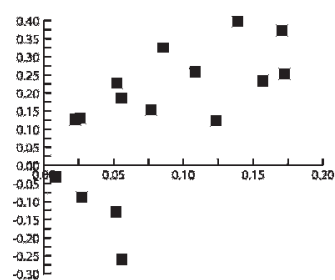

Palatal Width at $M 1$

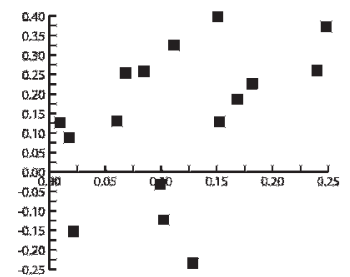

Upper C Width

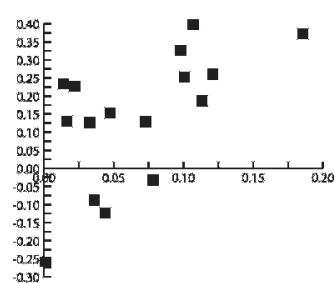

Upper M1 Ant. Width

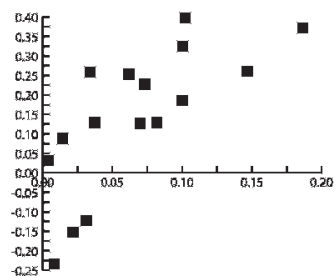

Facial Height

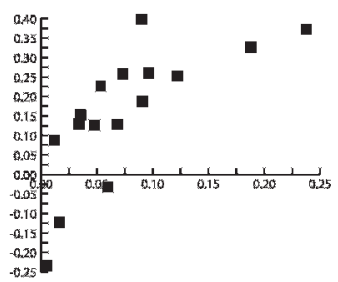

Mandibular Height

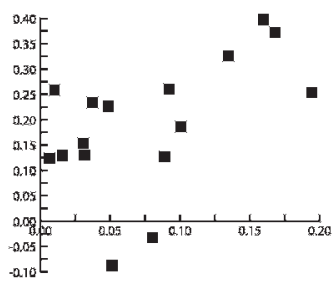

Upper Cheek Tooth Row Length

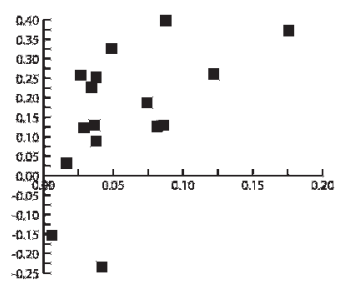

Width At Maxillary incisars

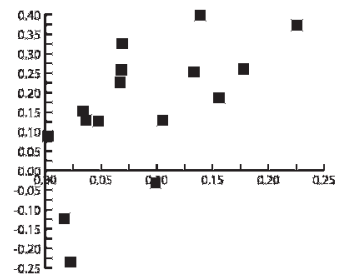

Upper P2 width

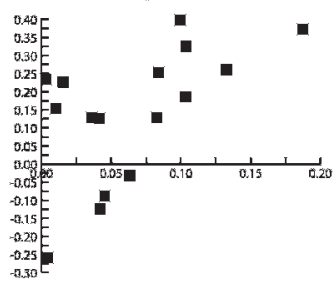

Upper M1 Pos. Width

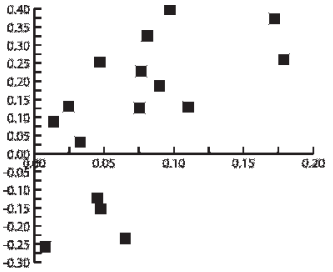

Vertical Facial Height.

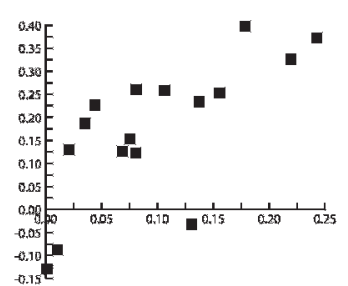

Morment Arm of Masseter

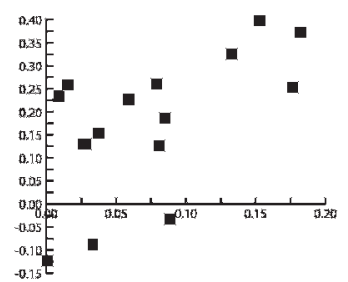

Lower Cheek Tooth Row Length

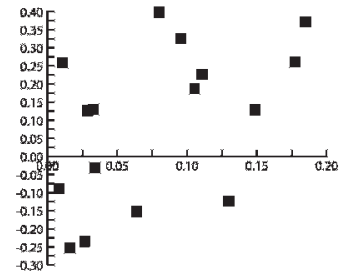

Upper I 1 Width

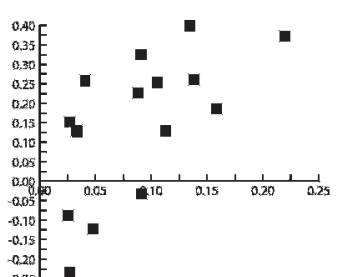

Upper P3 width

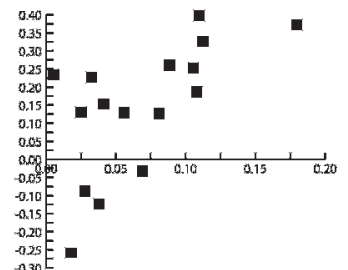

Upper MZ Ant. Width

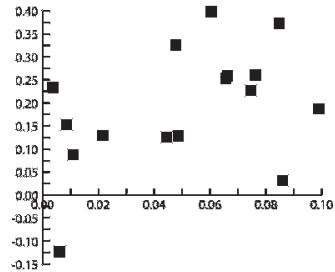

Temporal Chord

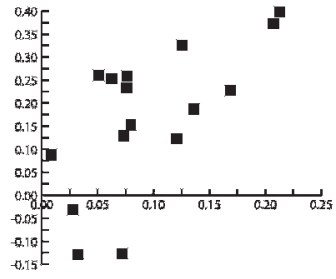

Moment Arm of Temporalis

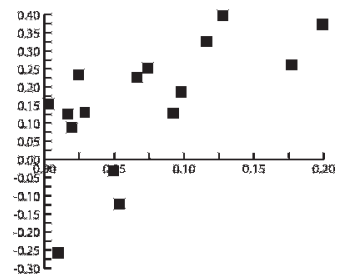

Palatal Length

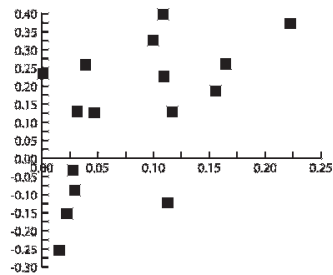

Upper 12 Width

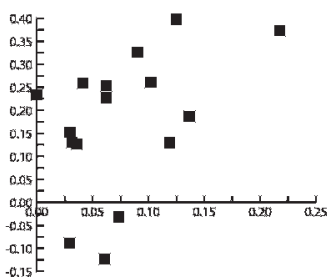

Upper P4 Width

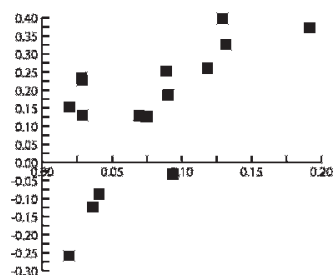

Upper M2 Pos. Width 


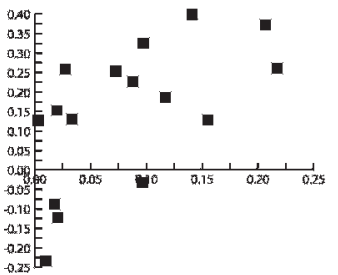

Upper P2 Length

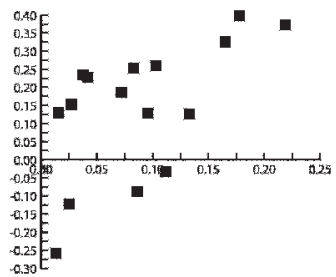

Upper M2 Length

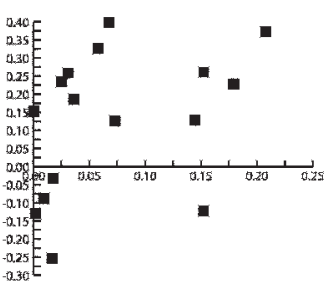

Lower 11 Width

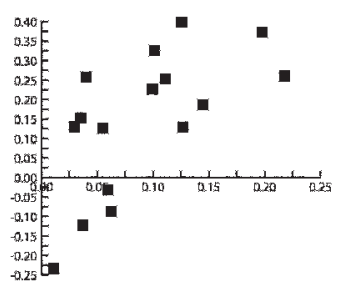

Lower P3 width

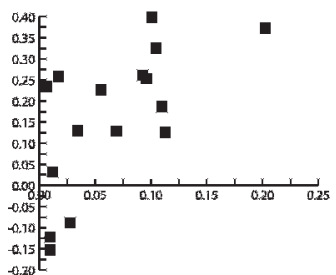

Lower M2 Ant. Width

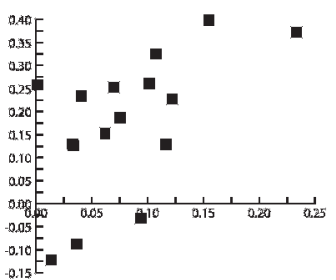

Lower P4 Length

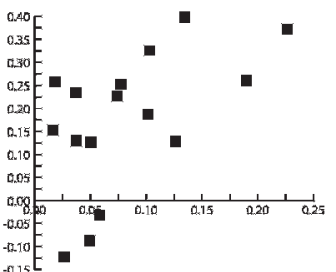

Upper P3 Length

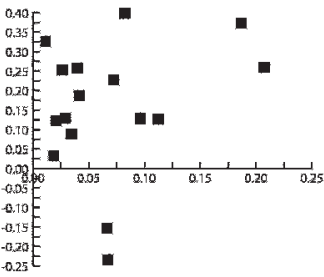

Upper 11 Length

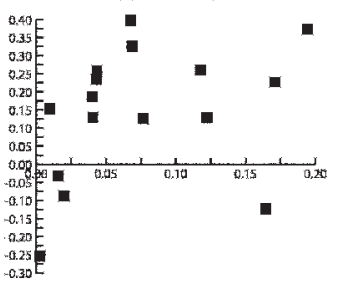

Lower 12 Width

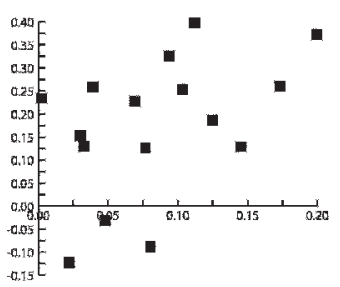

Lower P4 Width

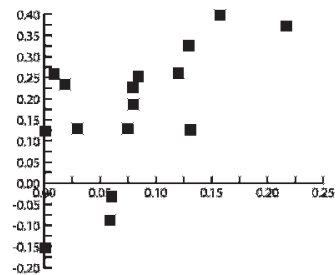

Lower M2 Pos, Width

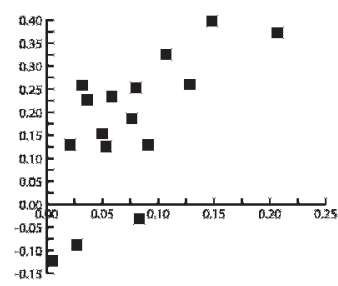

Lower MiLength

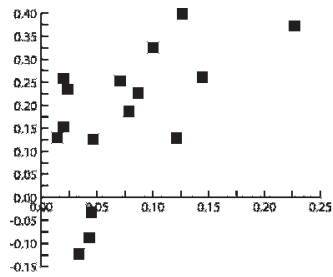

Upper P4 Length

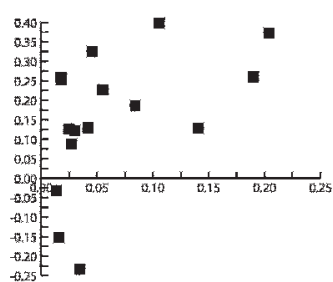

Upper 12 Length

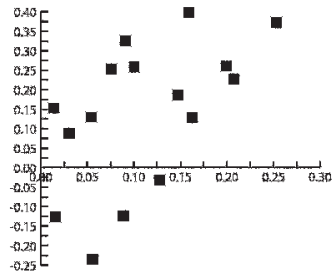

Lower C Width

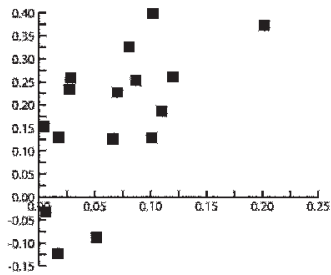

Lower M1 Ant Width

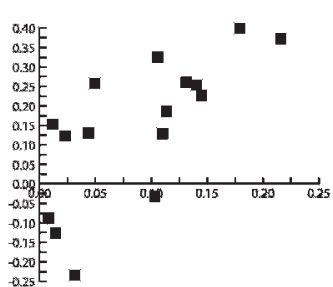

Lower P2 Length

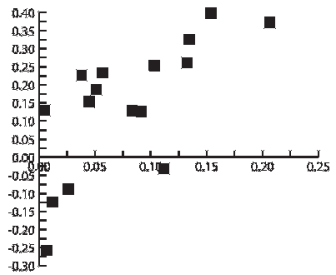

Lower M2 Length

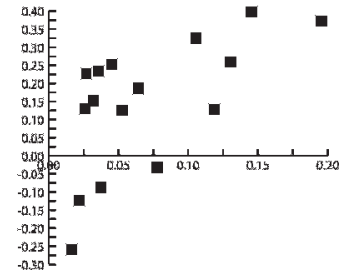

Upper M1 Length

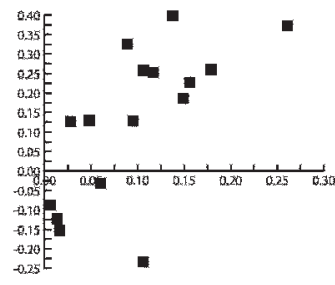

Upper C Length

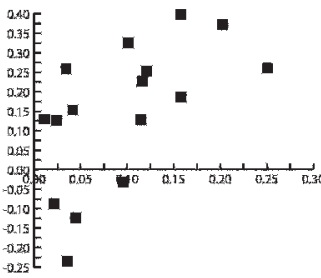

Lower P2 Width

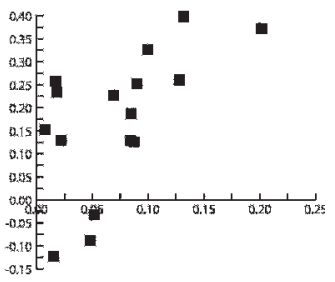

Lower M1 Pos. Width

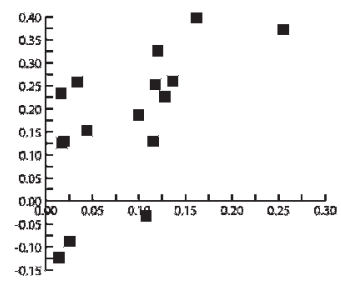

Lower P3 Length

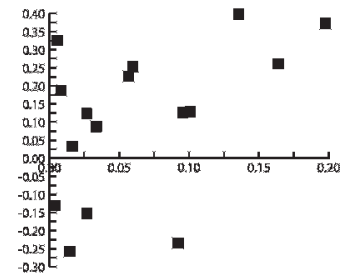

Lower l1 Length 

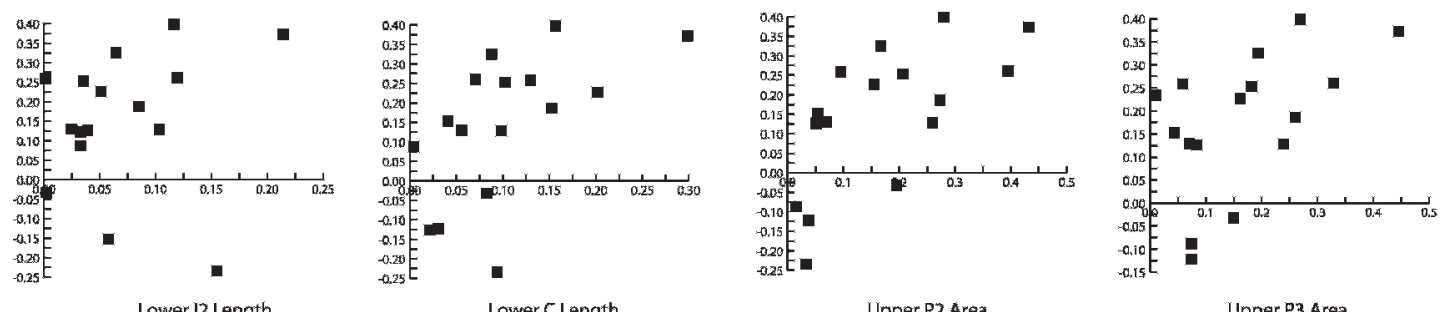

Upper P2 Area

Upper P3 Area

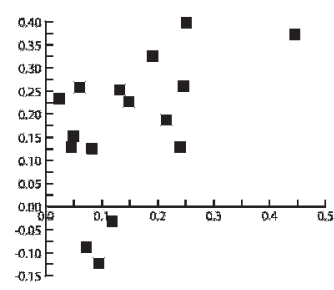

Upper P4 Area

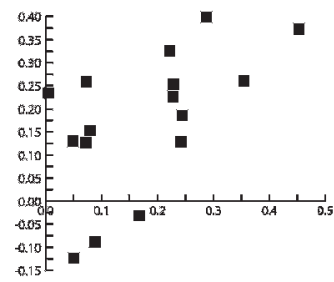

Lower P3 Area

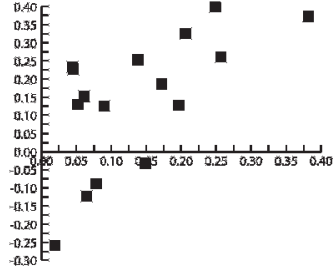

Upper M1 Area

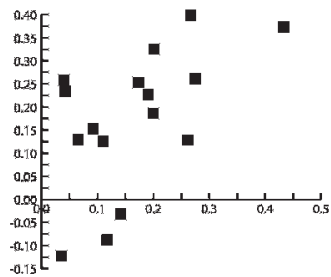

Lower P4 Area

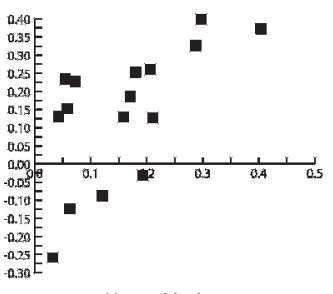

Upper M2 Area

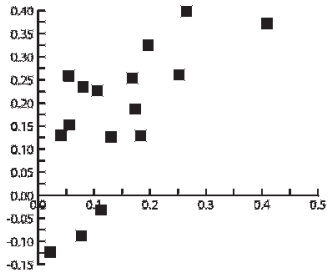

Lower M1 Area

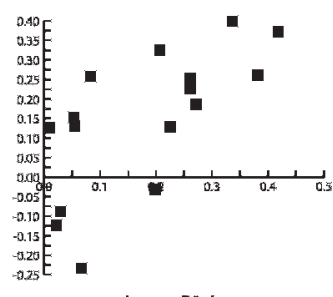

Lower P2 Area

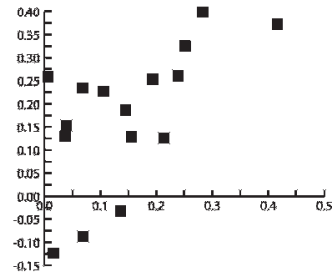

Lower M2 Area 


Complete lists of all issues of the Novitates and the Bulletin are available at World Wide Web site http://library.amnh.org/pubs. Inquire about ordering printed copies via e-mail from scipubs@amnh.org or via standard mail from: American Museum of Natural History, Library-Scientific Publications, Central Park West at 79th St., New York, NY 10024. TEL: (212) 769-5545. FAX: (212) 769-5009. 